\title{
Annäherungen zur Geschichte der Stadt Phaselis auf onomastischer Grundlage: Ein Studium der Namen aus Phaselis und ihrem Territorium
}

\author{
Phaselis Kentinin Tarihine Ilişkin Onomastik Temelli \\ Yaklaşımlar: Phaselis ve Teritoryumu'ndan Bilinen Isimlere \\ Yönelik Bir Çalışma
}

Nihal TÜNER ÖNEN

DPEN 2

PHASELIS: Disiplinlerarası Akdeniz Araştırmaları Dergisi'nde bulunan içeriklerin tümü kullanıcılara açık, serbestçe/ücretsiz "açık erişimli" bir dergidir. Kullanıcılar, yayıncıdan ve yazar(lar)dan izin almaksızın, dergideki makaleleri tam metin olarak okuyabilir, indirebilir, dağıtabilir, makalelerin çıktısını alabilir ve kaynak göstererek makalelere bağlantı verebilir.

PHASELIS: Disiplinlerarası Akdeniz Araştırmaları Dergisi uluslararası hakemli elektronik (online) bir dergi olup değerlendirme süreci biten makaleler derginin web sitesinde (journal.phaselis.org) yıl boyunca ilgili sayının içinde (Volume I: Ocak-Aralık 2015) yayımlanır. Aralık ayı sonunda ilgili yıla ait sayı tamamlanır.

Dergide yayımlanan eserlerin sorumluluğu yazarlarına aittir. Grundlage: Ein Studium der Namen aus Phaselis und ihrem Territorium". Phaselis I (2015) 3967. DOI: $10.18367 /$ Pha.15003 Kabul Tarihi: 09.02.2015 | Online Yayın Tarihi: 14.06.2015 


\title{
Annäherungen zur Geschichte der Stadt Phaselis auf onomastischer Grundlage: Ein Studium der Namen aus Phaselis und ihrem Territorium
}

\author{
Phaselis Kentinin Tarihine iliş̧in Onomastik Temelli Yaklaşımlar: \\ Phaselis ve Teritoryumu'ndan Bilinen Isimlere Yönelik Bir Çalışma
}

\author{
Nihal TÜNER ÖNEN*
}

Zusammenfassung: Dieser Artikel beabsichtigt anhand von Namen, die sich in epigraphischen und numismatischen Belegen und antiken Quellen finden lassen, die im Laufe der Zeit erfolgten Bevölkerungswechsel in Phaselis darzulegen und ebenfalls auf diese Weise über die Kulturkontakte und Handelsbeziehungen der Stadt zu informieren.

Schlüsselwörter: Phaselis · Onomastik · Polis · Kulturkontakte · Handelsbeziehungen

Öz: Bu makale, epigrafik ve nümizmatik belgeler ile antik kaynaklarda tespit edilen isimlerden yola çıkarak antikçağ boyunca Phaselis kentinde gözlemlenen halk hareketlerini ortaya çıkarmayı ve bu sayede kentin kültürel kontakları ve ticari ilişkileri hakkında bilgi vermeyi amaçlamaktadır.

Anahtar sözcükler: Phaselis · Onomastik · Polis · Kültürel Etkileşim · Ticari Illişki

Phaselis wurde Anfang des 7. Jhdts. v. Chr. von Kolonisten aus Lindos kolonisiert. Es befindet sich am südwestlichen Ufer des Pamphylischen Golfs, auf einer Halbinsel und ist von Lykien durch den Tahtalı Berg und das Klimaks Gebirge getrennt ${ }^{1}$. In dieser Zeit kolonisierten die rhodischen Siedler neben Phaselis auch die Städte Gagai, Melanippion, Korydalla und

* Yrd. Doç. Dr., Akdeniz Üniversitesi, Edebiyat Fakültesi, Eskiçağ Dilleri ve Kültürleri Bölümü, Antalya. nihaltuner@akdeniz.edu.tr

1 Phaselis war bis zur Eingliederung in den Lykischen Bund in späthellenistischer Zeit eine pamphylische Stadt. Dennoch wird die Stadt häufig von modernen Forschern irrtümlich mit Lykien verbunden, obwohl sie vor dem 2. Jhdt. v. Chr. keinerlei kulturelle und politische Bindungen mit der Lykischen Landschaft hatte.

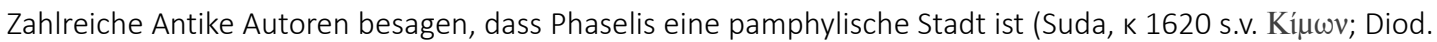
Bibl. XX. 27. 1; Strab. XIV. 2. 1; Dion. Per. 855; Sch. Thuc. II. 69. 1.1 f.; Eustath. Dion. Per. 855; Mela I. 79; Plin. Nat. Hist. V. 96; Ael. Herod. Pros. Cath. III. 1. 91. 13. Vgl. Tüner Önen 2008, 189-191). Die Bemerkungen des athenischen Harfners und Humoristen Stratonikos (der in der ersten Hälfte des 4. Jhdts. v. Chr. lebte) machen auch die Zugehörigkeit zu Pamphylien deutlich. Er erklärte die Phaseliten zu den größten Schuften unter den Pamphyliern, während die Sideten mit dem Urteil die größte Schuften der Welt noch schlechter wegkamen (Athen. Deip. VIII. 45. 6-13). Daneben beweisen die Inschriften, dass Phaselis bis zur späthellenistischen Zeit nicht zu Lykien zugehörte. Laut einem Ehrendekret aus Melonippion haben Melanippioten den Phaseliten Apollonios mit der Verleihung höher Privilegien und Ehrungen gedankt und ihm die Ernennung zum Proxenos und Euergetes gewährt. Denn er hatte sich um ihre Selbständigkeit bemüht, indem er sie in ein Freundschafts- und Bündnisverhältnis mit dem Demos der Rhodier aufzunehmen versuchte. Demnach war Phaselis nach dem Frieden von Apameia nicht unter die Herrschaft von Rhodos gefallen, sondern einige einflussreiche Phaseliten konnten sogar auch für andere Städte Autonomie erwirken (Adak 2007a, 42 f.; 2007b, 251-256). Die Stadt Phaselis prägte in der fraglichen Zeit von 188 bis 167 weiterhin Bronzegeld und vielleicht auch Silbergeld (Heipp-Tamer 1993, 84 ff.). 
Rhodiapolis an der lykischen Küste ${ }^{2}$, Tarsos und Soloi an der kilikischen Küste ${ }^{3}$, um sich an den gewerblichen Tätigkeiten im östlichen Mittelmeer beteiligen zu können ${ }^{4}$. Phaselis lag auf dem Seeweg von der Ägäis nach Zypern, Ägypten und der Levante. Die Stadt nutzte diese günstige Lage zu ihrem Vorteil und entwickelte sich sehr schnell zu einer Seefahrer- und Handelsstadt ${ }^{5}$.

Für Phaselis liegen bisher annähernd 240 Anthroponyme vor, die sich mit 318 Personen in Verbindung bringen lassen. Diese Anthroponyme zeigen auf, dass Phaselis besonders im klassischen und hellenistischen Zeitalter mit dem östlichen Mittelmeerraum, vor allem mit den Ägäischen Inseln und Hellas in Kontakt war. Denn bisher wurden viele Phaseliten in Rhodos, Athen, Delphi, Delos, Samos, Karpathos, Euboia, Kos, Oropos Thespiai, Theben, Philai und

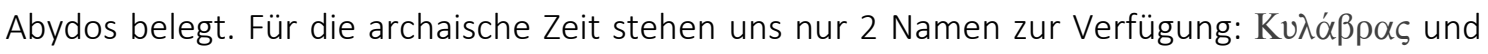
$\Lambda$ ákı̧. Beide Personen werden in antiken Quellen und auf einer Inschrift erwähnt ${ }^{6}$. Lakios war mytischer Gründer von Phaselis; Kylabros hingegen ein indigener Hirte, bei dem Lakios das Gebiet von Phaselis kaufte, um es zu kolonisieren.

Dagegen erhöht sich die Zahl der Namen in der klassischen Zeit. Für die Zeit zwischen den

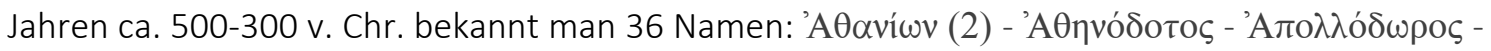

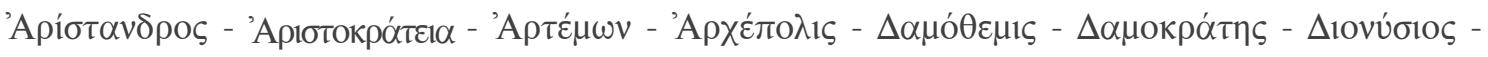

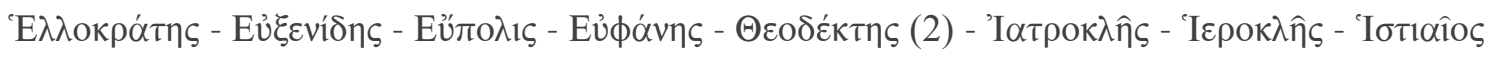

2 Gagai (Etym. Mag. 219.6-11), Melanippion (Adak 2007a, 42; 2007b, 275), Korydalla (FGrHist la, 1 frg. 246; Steph. Byz. 376) und Rhodiapolis (FGrHist 2b 115, F 103. 15).

Tarsus (Strab. XIV. 5.12) und Soloi (Strab. XIV. 5. 8).

Für rhodische Kolonisation im Mittelmeer im VII. Jhdt. v. Chr. s. Malkin 2011, 72-81.

5 Die Bedeutung von Phaselis als Handelstadt began schon mit der ersten Hälfte des VII. Jhdts. v. Chr. Herodot berichtete, dass Phaselis auch unter den Städten war, die an der Gründung Hellenions in der ägyptischen Handelsstadt Naukratis im VII. Jhdt. v. Chr. teilgenommen hatten (Hdt. II. 178). Im Verband der neun Städte zur Erstellung dieses Hauptheiligtums war sie als einzige Stadt aus der anatolischen Südküste vertreten (vgl. Möller 2000, 75, 79; Tüner Önen 2008, 96 ff.; Tüner Önen 2012a, 206). Auch ihre Münzen bezeugen ihre Bedeutung für die Nautik und den Handel. Auf ihnen ist der vordere Teil eines Schiffes abgebildet, ein Motiv, das während der gesamten klassisch-hellenistischen Epoche beibehalten wurde (Heipp-Tamr 1993, 11, 25). Die Vorderseite einer Münze verfügt auch über ein Schiffsbug, auf dem eine nach rechts zeigende Statue des Hermes steht, während auf der Rückseite der Münze ein Schiffsheck zusammen mit dem Name Nausinikos abgebildet ist (Heipp-Tamer 1993, 134 no: 88-89 taf. 5). Die Rückseite zeigt ebenfalls das Symbol von Hermes kerykeion. Das Bild des Handelsgottes Hermes verdeutlicht, dass der Handel von Phaselis unter seinem Schutz stand (vgl. Tekin 2012, 80-81). Die große

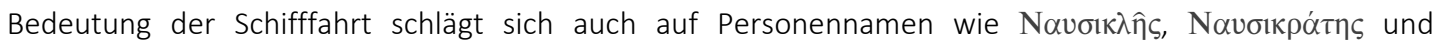
Navoívikoৎ nieder (Heipp-Tamer 1993, 134 no: 88-89 (taf. 5); 140 no: 155 und 159 (taf. 9). Vgl. Tüner Önen 2012a, 208; Adak 2013, 67). Dass Münzen aus Phaselis in den Schatzfunden in Ägypten, Syrien und Rhodos vorhanden waren, weist auf Handelsbeziehungen zwischen Phaselis und diesen Ländern in der archaischen und klassischen Zeit hin (IGCH 1185, 1482, 1637, 1640, 1644, 1645; CH IV 5-6. Vgl. Robinson 1930, 93-106; Kraay - Moorey 1968, 226; Kraay 1976, 273; Kraay 1977, 189-198; Hurter - Pásztory 1984, 111 ff.; HeippTamer 1993, 25-47). Auch auf Inschriften findet man bereits frühe Belege für die Beteiligung der Phaseliten am Seehandel: So weihten die beiden Naukleroi (oder emporoi) Nikandors und Polyainetos im V. Jhdt.v. Chr. den Zehnt des aus dem Seehandel erworbenen Gewinns der Stadtgöttin Athena Polias (TAM II 1184. Vgl. Tüner Önen 2012a, 208). Das Akhikar Pergament, welches das aramäische Zollregister aus Elephantine enthält, macht Handelsbeziehungen in der ersten Hälfte des V. Jhdts V. Chr. zwischen Phaselis und Ägypten deutlich. Während darin kein griechisches Schiff und nur 6 phönizische Schiffe beschrieben sind, wurden 36 ionischen Schiffe aus Phaselis dokumentiert. Man vermutet, dass unter dem Adjektiv lonisch (=ywyn $p s^{d}{ }^{\prime} r{ }^{\prime} y$ ), die rund um Phaselis lebenden Griechen gemeint sein könnten (Briant - Descat 1998, 69-72; Bresson 2000, 68-73).

6 FGrHist 448 F1; Ael. Herod. Pros. Cath. III. 1. 253; Blinkenberg 1941, 169-171, No: 2. 


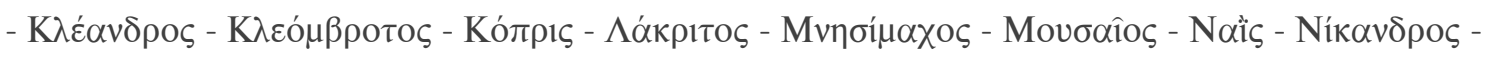

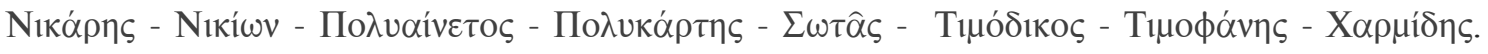
Auffällig ist, daß sämtliche Namen griechisch sind. Der rhodische Einfluß mancher Namen ist in seiner dorische Form deutlich. Dieses Phänomen hielt sich bis in die Kaiserzeit. Athanion, Damothemis, Damokrates und Mnasimakhos sind im dorischen Dialekt verfasst.

In dieser Zeit wurden die Existenz vieler Phaseliten in Athen (13), Delphi (4) und Samos (2) durch zahlreiche Inschriften und antike Quellen belegt ${ }^{7}$. Der Dichter Theodektes, sein Sohn Theodektes, Grammatiker Dionysios und Mnesimakhos, die in antiken Quellen erwähnt wurden, lebten vielleicht in Athen. Es ist nicht überraschend, dass 13 Phaseliten in Athen lebten. Eine auf das Jahr 450 v. Chr. datierende, in Athen gefundene Inschrift informiert über die Beziehungen der Phaseliten zu Händlern aus Athen ${ }^{8}$. Die Inschrift beinhaltet ein Dekret des Rates und Volkes von Athen bezüglich phaselitischer Händler, die damals mit Athenern handelten. Außerdem berichtete der bekannte Redner Demosthenes, dass drei phaselitische Händler (Artemon und sein Bruder Lakritos und Apollodoros) in Athen ein Darlehen bei Androkles und Nausikrates aufnahmen, es aber nicht zurückzahlten? .

Die hellenistische Zeit bietet ein wesentlich reicheres Namensmaterial (150 Personen):

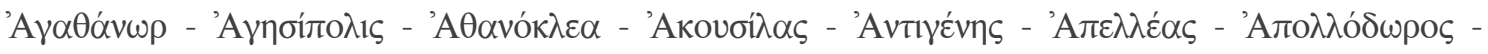

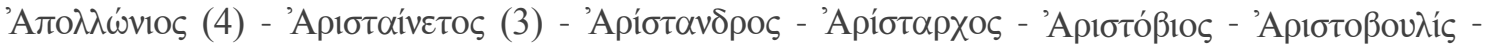

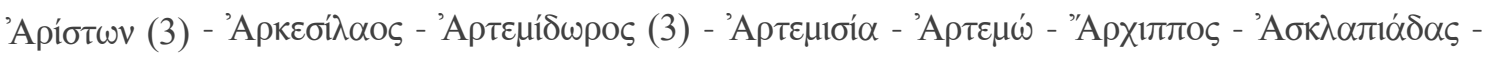

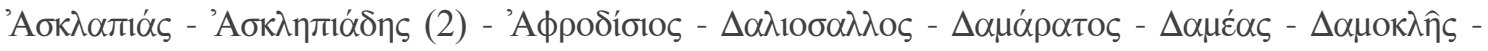

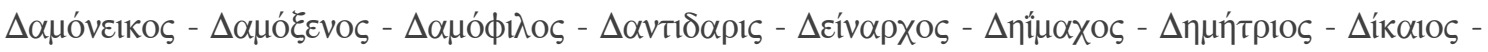

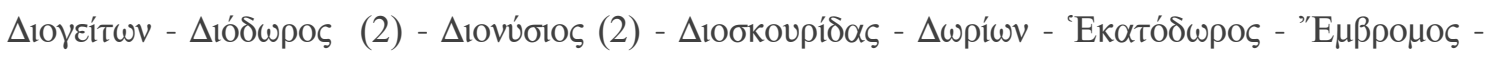

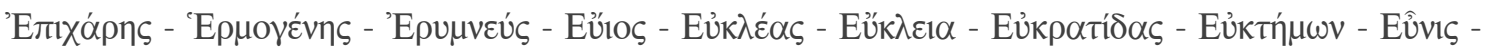

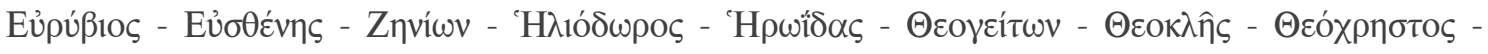

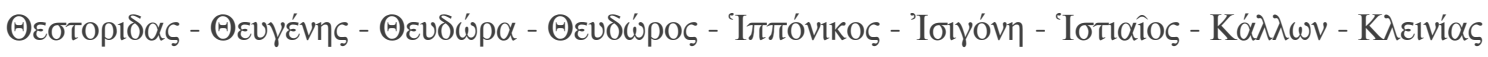

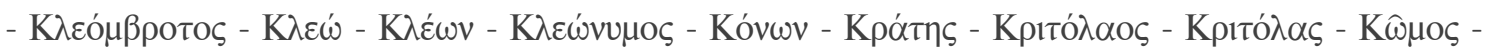

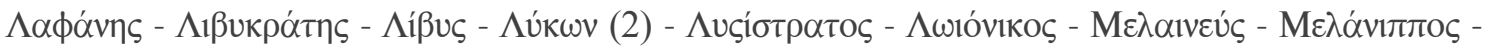

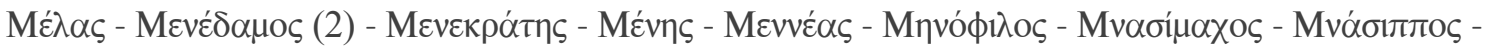

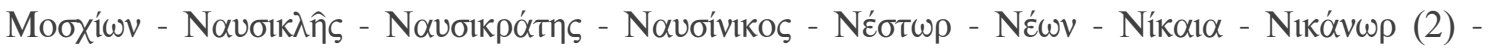

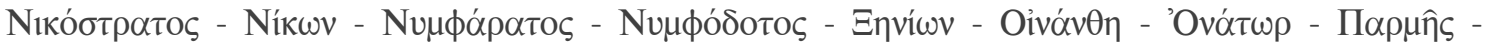

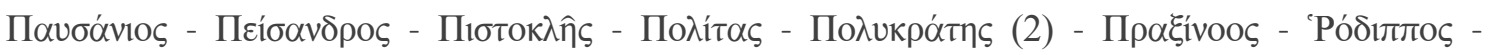

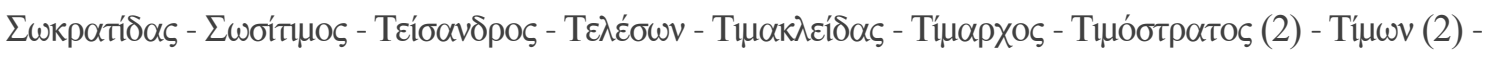

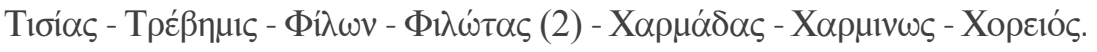

84 Namen unter denen kommen auf Münzen vor, die die Stadt zwischen 250 und $130 \mathrm{v}$. Chr. prägte ${ }^{10}$. Die überwiegende Mehrzahl der Namen sind griechisch. Die nichtgriechischen

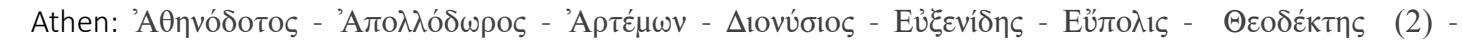

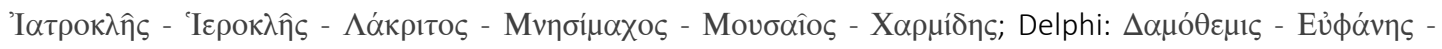

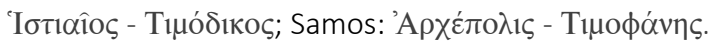

$8 \quad$ IG I3 10. Vgl. Jameson 2000-2003, 23-29 taf. 3-4.

9 Demosth. Contr. Lacr. XXXV.

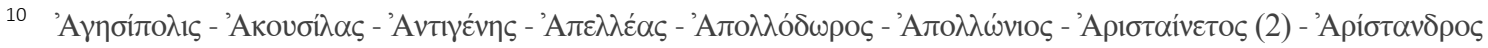

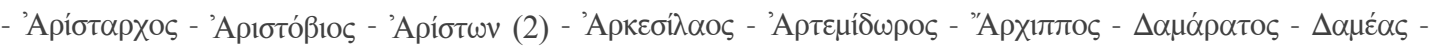

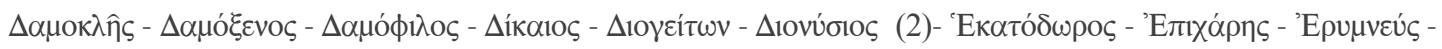




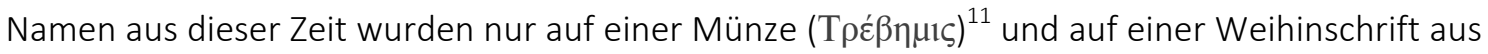
den II.-I. Jhdt. V. Chr. in Mnara innerhalb des Territoriums von Phaselis ( $\Delta \alpha \lambda_{10 \sigma} \sigma \lambda \lambda_{0}$ o $\Delta \alpha v \tau 1 \delta \alpha \rho ı \varsigma$ - "Е $\mu \beta \rho о \mu о \varsigma)$ dokumentiert ${ }^{12}$. Viele Namen sind auf Ägäischen Inseln und Hellas sehr beliebte Namen. Besonders treten die theophoriken Namen hervor ${ }^{13}$. Im Übrigen ist es

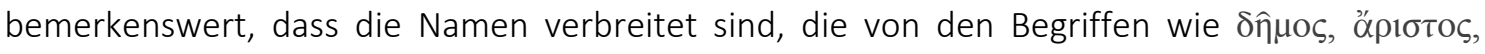

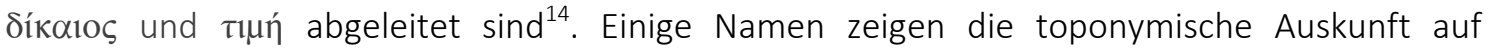

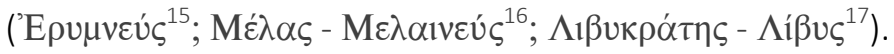

Die Tatsache, dass man viele Phaseliten in dieser Zeit im Ausland findet, zeugt von einer hohen Mobilität. Neben Handelszentren wie Delos oder Athen war vor allem Rhodos ein bevorzugter Aufenthaltsort. Auf Rhodos sind 31 Phaseliten durch beinahe ebenso viele Inschriften bezeugt ${ }^{18}$. Beim überwiegenden Teil der Inschriften, in denen Phaseliten genannt werden, handelt es sich um Grabsteine. Dementsprechend haben sich viele Phaseliten auf Rhodos niedergelassen. Außer Grabinschriften wurden auch meistens Ehreninschriften für Phaseliten gefunden, die Mitglieder der verschiedenen kultischen Fremdenvereine auf Rhodos waren. Auf Lindos wurde von Phaseliten eine Weihung für Athena Lindia vorgenommen. In dieser Inschrift wurde auch aufgrund der Jahrbücher des Ksenagoras berichtet, dass die Phaseliten unter der Führung von Lakios gegen Solymern kämpften. Die auf Rhodos gefundenen Inschriften weisen auch auf die Kontinuität der Beziehungen zwischen Phaselis und Rhodos hin. Diese Folgerung bestärken die Mehrzahl der Namen im dorischen Dialekt in dieser Zeit ${ }^{19}$.

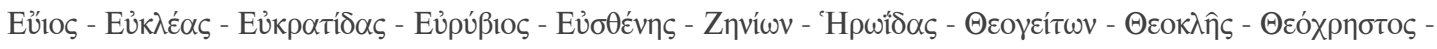

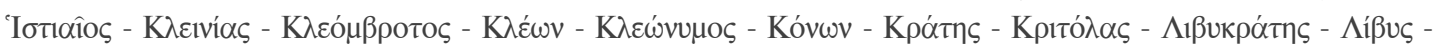

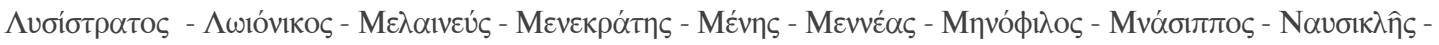

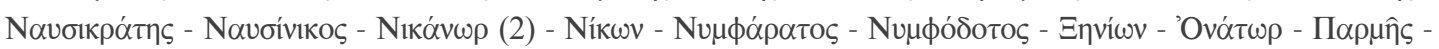

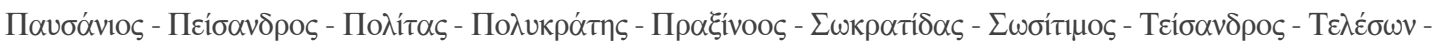

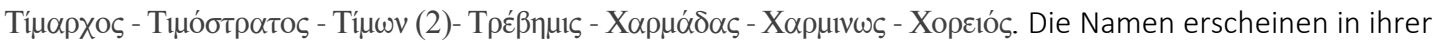
Mehrzahl im Nomitaniv. Es dürfte sich um Beamte der Stadt handeln, die mit der Münzprägung betraut waren. Bei den wenigen, im Genitiv erscheinenden Namen haben wir es wahrscheinlich mit den führenden Amtsträgern (am ehesten die demourgoi) zu tun. Dafür s. Heipp-Tamer 1993, 56-58.

11 Vgl. Zgusta 1964, § 1600-4.

12 Für diese Inschrift und Mnara innerhalb des Territoriums von Phaselis s. Şahin - Adak 2013, $300 \mathrm{ff}$.

13 'А $А$

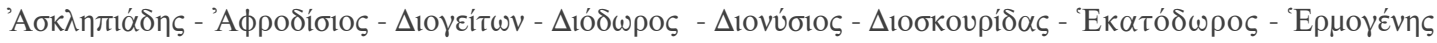

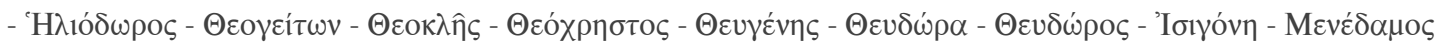

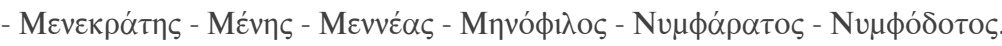

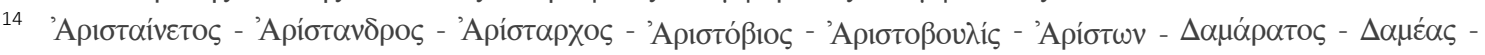

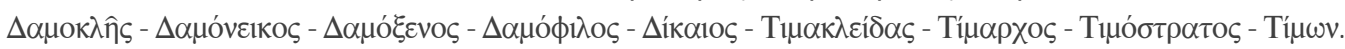

15 Der Name 'Epupveúc wurde von L. Robert mit dem im oberen Lauf des Melas gelegenen Ort Erymna/Orymna in Verbindung gebracht (Robert 1963, 307; vgl. Zgusta 1964, § 360-2; Adak 2013, 72).

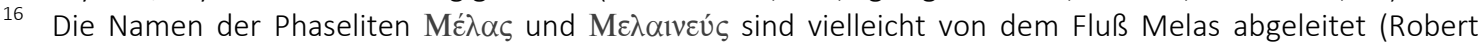
1963, 407; vgl. Adak 2013, 72).

17 Die Namen sind offensichtlich von Libya abgeleitet.

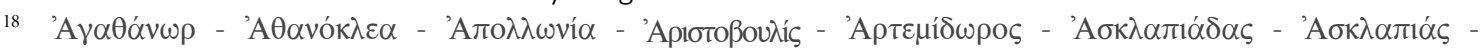

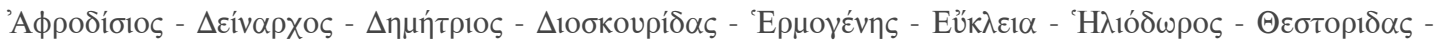

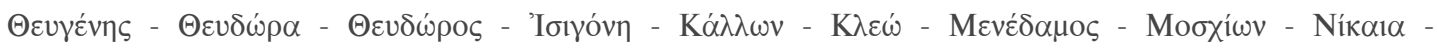

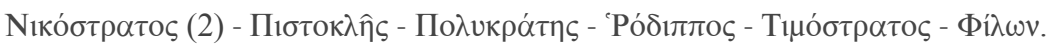

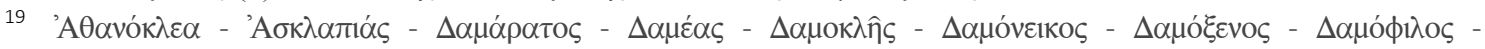

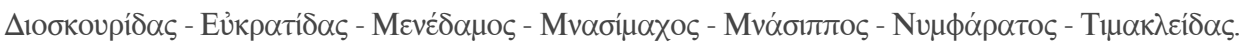


In dieser Zeit wurden durch Inschriften 14 Phaseliten auf Ägäischen Inseln (Euboia, Delos, Kos, und Karpathos) und in Boiotia (Oropos, Thespia) belegt ${ }^{20}$. Tisias, Sohn des Asklepiades mietete eine Werkstatt auf Delos für 210 Drachmen; Philotas war Ephebe auf Delos; Apollonias, der Sohn des Laphanes, war ein Ringer und gewann den 2. Platz beim Agon der Pythia auf Kos. In Ägypten (Theben, Philai, Abydos) wurden auch 6 Phaseliten dokumentiert ${ }^{21}$. Die meisten von innen besuchten die bekannten Denkmäler im Tal der Könige. Hingegen war Nestor ein Offizier im ptolemäischen Dienst. Er war Phrouriarch, Gerrophylax und stellvertretender Strategos von Syene, Elephantine und Philai.

In der römischen Zeit wurden bisher 101 Namen in Verbindung mit 128 Personen bestimmt:

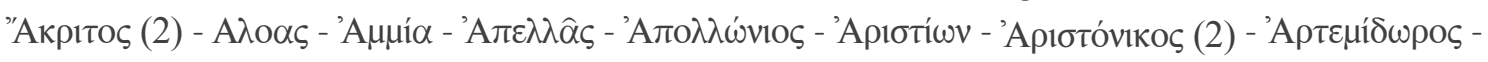

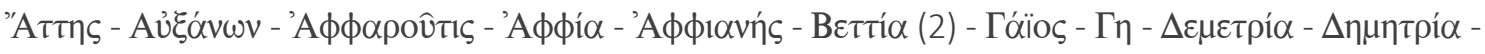

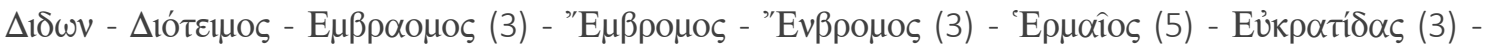

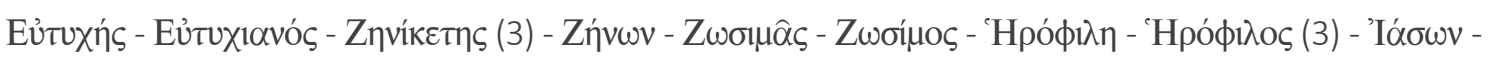

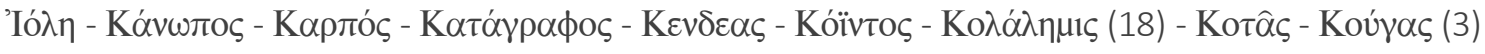

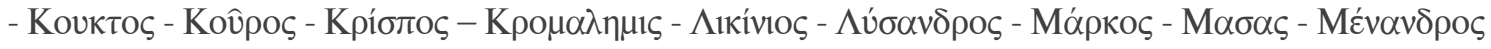

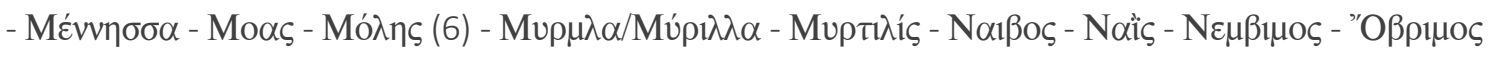

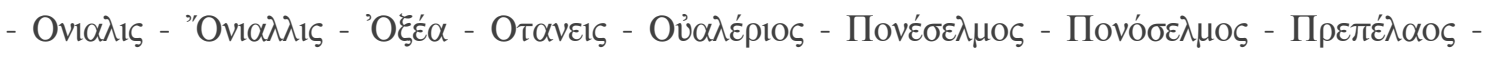

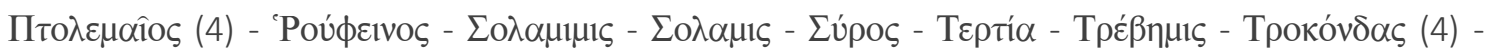

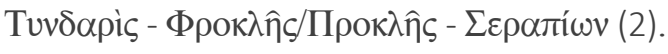

49 Personen unter denen fanden sich im Territorium (Kocaköy, Yarbaşçandır, Zindanyakası, Mnara, Havuzönüdamı, Armutçuk, İncircik, Fıllara), 3 Personen in Lykien (Melanippion, Olympos) und 2 Personen in Karien (lasos) ${ }^{22}$. In der Kaiserzeit waren Phaseliten im Ausland kaum zu finden. Aufgrund des epigraphischen Materials lässt sich feststellen, dass die hohe Mobilität, die für die klassische und hellenistische Zeit ein charakteristisches Merkmal der Phaseliten war, verschwand. Die mitten in der 2. Hälfte des 2. Jhdts. v. Chr. (ca. 130) begonnene Mitgliedschaft des lykischen Bundes hat ungefähr 30 Jahre angedauert ${ }^{23}$. Die im ersten Jahrhundert v. Chr. über das Mittelmeer erfolgten seeräuberischen Tätigkeiten, haben das Schicksal von Phaselis erheblich verändert. Phaselis war als Seeräuberstadt verrufen, denn sie stand um 80 v. Chr. unter der Kontrolle des Piratenhäuptling Zeniketes, der von seinem gleichnamigen Residenz auf dem Berg Olympos (Musa Dağ), unweit südlich von Phaselis die gesamte Region bis zum Eintritt in die Pamphylische Ebene beherrschte. Nachher wurde die Stadt von Publius Servilius Vatia (Isauricus), der im Jahr 77 v. Chr. von Rom gegen diese Seeräuber entsendet wurde, bestraft und sie verlor zumindest einen Teil ihres Territoriums als ager publicus ${ }^{24}$.

20

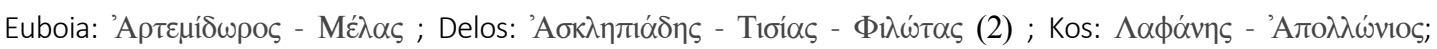

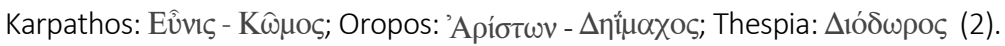

21

22

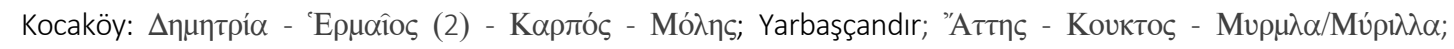

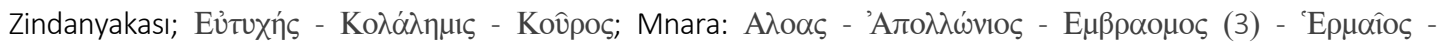

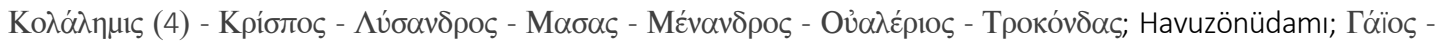

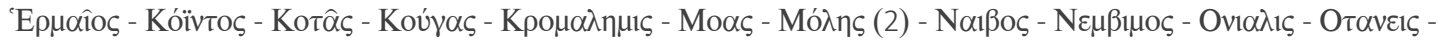

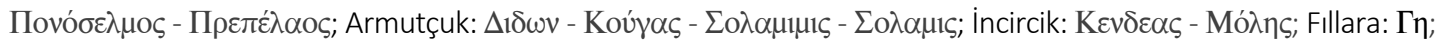

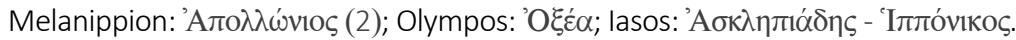

23 Dafür s. Tüner Önen 2012b, 481 Anm. 19.

24 Cicero, In Verr. II 4. 21; Strab. XIV 5. 7; Oros. Hist. V 23. 22; Flor. epit. I 41. 6; Eutrop. Berv. VI 3. Für ager 
Die römischen Säuberungsaktionen des Meeres von Piraterie haben die Bevölkerung der Küstenstädte an der südwestlichen Küstenlinie von Kleinasien stark dezimiert. Den Bevölkerungsrückgang in Phaselis belegt eine Nachricht bei Lukan. Pompeius fand die Stadt weitgehend entvölkert vor, als er 48 v. Chr. auf seiner Flucht nach Ägypten vor der Stadt $a_{\text {ankerte }}^{25}$. Aus Lukans Beschreibung von Phaselis und aus dem Studium der kaiserzeitlichen Anthroponyme werden deutlich, dass nach den Seeräuberkriegen ein Wandel in der Bevölkerungsstruktur der Stadt eintrat. Demnach verschwand die alte Obersschicht grösstenteils und wurde durch Mitglieder anatolischer Herkunft ersetzt. Deshalb bietet die Kaiserzeit gegenüber den vorausgegangenen Epochen ein recht inhomegenes Bild. Während die Zahl der griechischen Namen sich verringerte (38 Anthroponyme $)^{26}$, stiegen die indigenen Namen im Vergleich zu den klassischen und hellenistischen Zeiten (35 Anthroponyme) ${ }^{27}$. Lateinische Namen sind relativ gering ${ }^{28}$. Es ist besonders bemerkenswert, dass die im Territorium der Stadt bestimmten Namen grossenteils indigen sind ${ }^{29}$.

Die zahlreichen Personen mit indigenen Namen scheinen die Oberschicht der Stadt zu bilden ${ }^{30}$. Die Homonymität war unter den indigenen Namen weit verbreitet. 18 Personen trugen den Namen Kolalemis, der bisher nur in Phaselis (für 13 Personen) und ihrem Territorium (für 5 Personen) belegt worden sind. Sie haben größtenteils ein Verwandtschaftsverhältnis. Kolalemis, der den Namen bereits in der 6. Generation führte, hatte die führende Position in der Stadt ${ }^{31}$. Als Träger des Namens Embromos sind 5, für Moles und Trokondas jeweils 3 Personen bezeugt.

publicus s.: Cicero, Leg. Agr. II 50. Vgl. Arslan 2003, 101-105.

25 Luc. Bel. civ. VIII. 249-55: “... da strecht sich entgegen der Seefarth aus Pamphylias Boden - Noch hatte gewagt er nicht, irgend Mauern sich anzuvertraun; dich, geringes Phaselis, zum Ersten. Magnus betrat! Denn die schwache Bewohnerschaft, Häuser entleert der Leute, benahmen die Furcht ihm vor dir; war der grösser am Bord des Schiffes die Mannschaft als deine!" (Übersetzen: Dikander 1839,163f.).

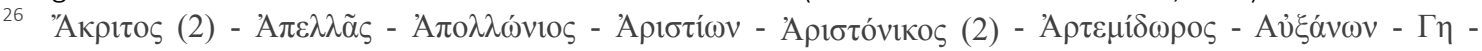

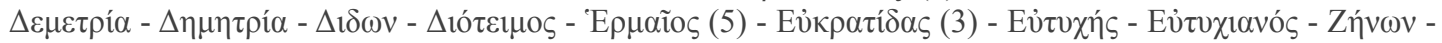

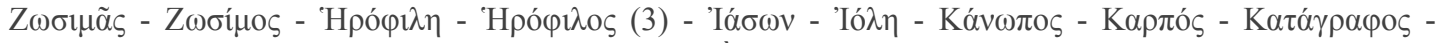

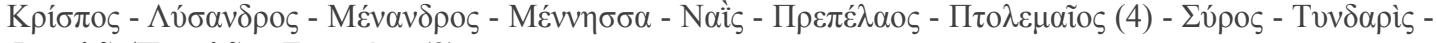

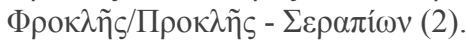

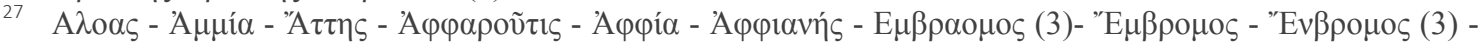

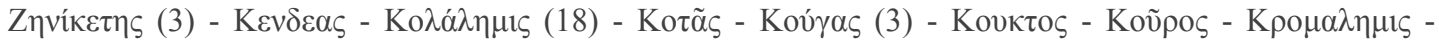

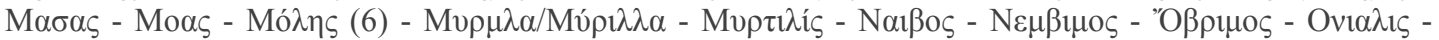

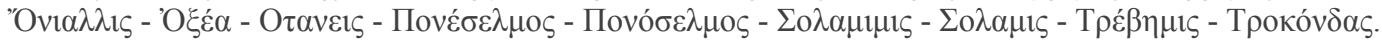

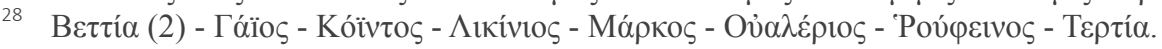

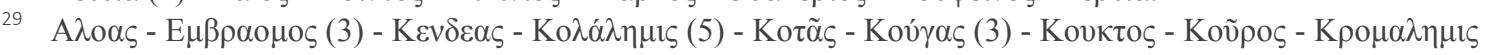

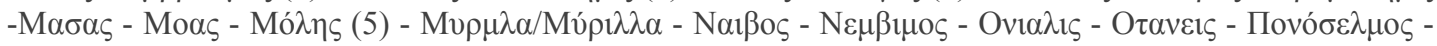

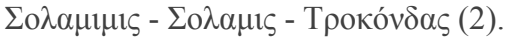

30 Aurelia Apphia stiftete für ihre Vaterstadt den Agon Palladeius (TAM || 1206). Der Ringer Kougas war sicherlich ein weiteres Mitglieder der Oberschicht (TAM II 1207; Adak et al. 2006, 9 f. no: 6). Ptolemaios, der Sohn von Kolalemis war einer der führenden Männer der Stadt mit hohen Priesterstellen, Eikosaprotos, und

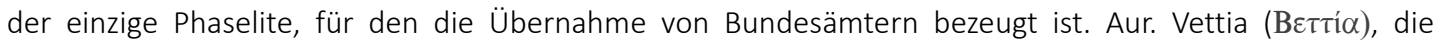

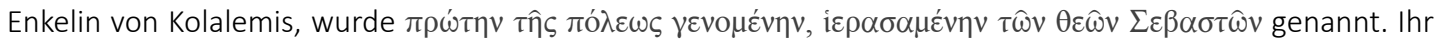
Mann Zeniketes der Dritte hatte auch alle städtischen Ämter inne. Der Name Zeniketes weist darauf hin, dass der "Piratenchef" Zeniketes in römischer Zeit noch Achtung in der Stadt genoss. Der Name ist uns meist aus dieser Region bekannt. Für die Mitgliedern der Oberschicht von Phaselis auch s. Tüner Önen 2008.

31 Kolalemis hatte alle städtischen Ämter (Eikosaprotos bis zu seinem Tod, Prytan, Grammateus des Rats, Gymnasiarch und Epimeletes öffentlicher Bauten) inne und 2 Gesandtschaften übernommen. Für Kolalemis und sein Familie s. Tüner Önen 2008, 331 ff.; vgl. Adak 2013, 75 f. 
Wie man sehen kann, hat sich die ethnische Zusammensetzung der Stadtbevölkerung im Laufe der Zeit erheblich verändert. In klassischer und hellenistischer Zeit waren alle Namen bis auf den 4 Personen griechisch. In dieser Zeit war der rhodische Einfluß in der dorischen Form vieler Namen deutlich faßbar. Hingegen nahm die Anzahl der indigenen Namen in römischer Zeit allmählich zu. Folglich wird deutlich, dass Phaselis ihren griechischen Charakter durch die klassische und hellenistische Zeit hindurch vollständig bewahrt hat. Aber wegen der Ereignisse im ersten Jahrhundert v. Chr. und die verfassungsmäßigen Entwicklungen unter der römischen Herrschaft, veränderte sich die Bevölkerung der Stadt. Phaselis war in der Kaiserzeit nicht mehr eine bedeutende Handelsmetropole, weil die maritime Komponente, der Phaselis seinen Wohlstand verdankte, kaum eine Rolle mehr spielte.

\section{Namens-Liste von Phaseliten}

1- 'A $\quad$ $\gamma \alpha \theta \alpha ́ v \omega \rho$ (1): $\quad$ Der Name ist in einer agonistischen Inschrift (I. Jhdt. v. Chr.) aus Rhodos

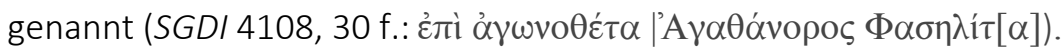

2- 'Aүпбítoגis (1): Der Name kommt auf einer Münze (ca. 250-220 v. Chr.) vor (HeippTamer 1993, 136 no: 112, taf. 6).

3- 'A $\theta \alpha v^{\prime} \omega v(2)$ :

Der Name wird in den zwei Inschriften in Phaselis erwähnt (IV. Jhdt. v.

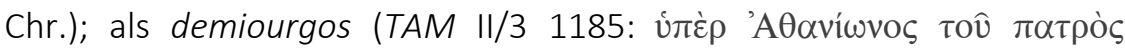

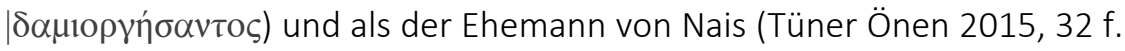

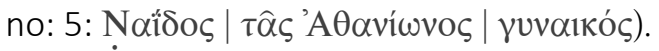

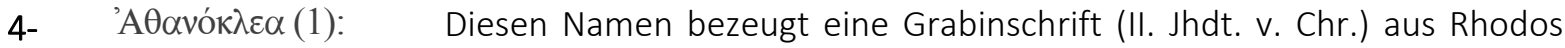

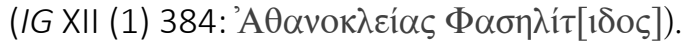

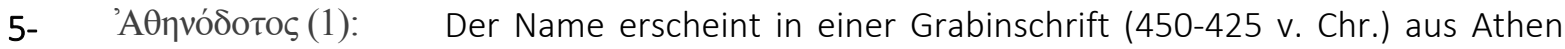

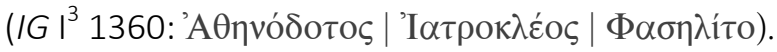

6- "Aкрітоৎ (2):

Die Namen werden auf zwei Agoninschriften (II-III. Jhdt. n. Chr.) in Phaselis dokumentiert. Der Vater und der Sohn trugen gleiche Namen

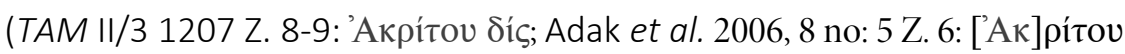
$\left.\beta^{\prime}\right)$.

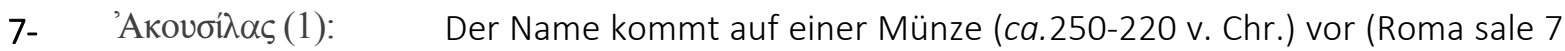
(2014) 711).

8- $\quad \mathrm{A} \lambda \mathrm{o \alpha \varsigma}(1)$ :

Der Name liegt auf einer Weihinschrift (Kaiserzeit?) aus Mnara vor (SEG

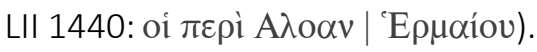

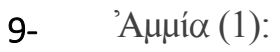

Der Name wird in einer Grabinschrift (II-III. Jhdt. n. Chr.) in Phaselis

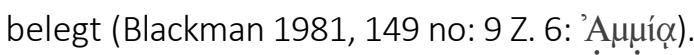

10- 'Avtıyévns (1): Der Name kommt auf den Münzen (ca.167-130 v. Chr.) vor (HeippTamer 1993, 158 f. no: 359-360 taf. 28).

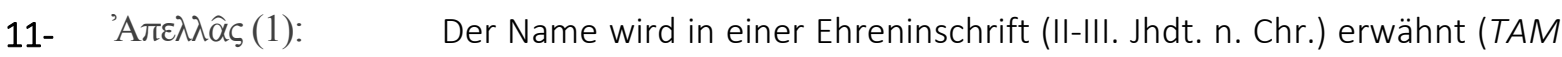
II/3 1204 Z. 3: $\left.\tau 0 \hat{v}{ }^{\prime} A \pi \varepsilon \lambda \lambda \hat{\alpha}\right)$.

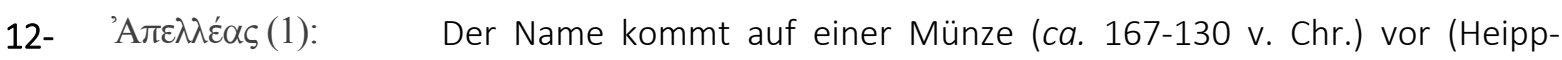
Tamer 1993, 175 no: 3). 


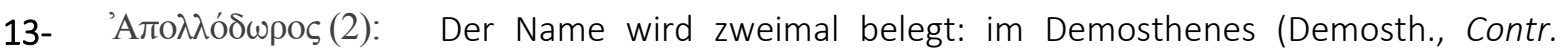
Lacr.XXXV. 10); auf der Münze (Heipp-Tamer 1993, 134 no: 90-91 taf. 5). Erster war ein Händler aus dem IV. Jhdt. v. Chr.; Zweiter war ein Beamter, der für die Münzprägung zwischen den Jahren 250-220 v. Chr. verantwortlich wäre.

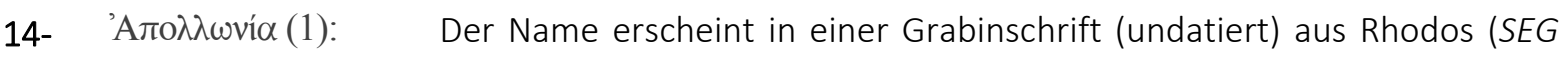

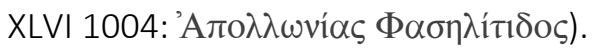

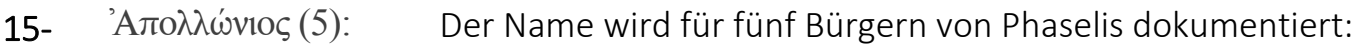

1-2) Auf einer Ehreninschrift aus Melanippion, die kurz nach dem Jahr 188 v. Chr. datiert wird (SEG LVII 1663, Z. 11 und 12: 'A $\pi\left[\mathrm{o} \lambda \lambda \omega_{\text {vviov] }}\right.$ 'А

3) Auf einer Siegerliste von Asklepieia im Kos, die in die Zeit zwischen ca. 200 und 168 v. Chr. datiert werden kann (Klee 1918, 122 no: 8 Z. 49 f:

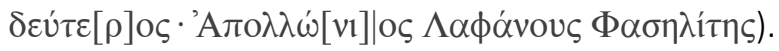

4) Auf den Münzen (ca. 167-130 v. Chr.) (Heipp-Tamer 1993, 158 no: 348-350 taf. 27f.).

5) Auf einer Weihinschrift aus der Kaiserzeit (?) in Mnara (SEG LII 1444:

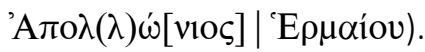

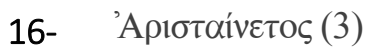

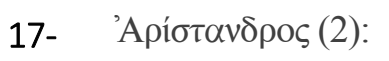

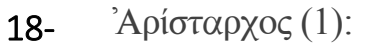

19- 'Apiotíwv (1):

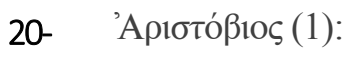

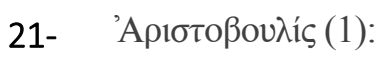

22- 'Арıбтокра́
Der Name wird für drei Bürgern von Phaselis belegt:

1-2) Auf den Münzen, die zwischen den Jahren ca. 250-220 v. Chr. (Heipp-Tamer 1993, 134 no: 93-94 taf. 5) und zwischen den Jahren ca. 167-130 v. Chr. (Heipp-Tamer 1993, 158 no: 357 taf. 28) geprägt wurden.

3) Die Person war ein Historiker (die hellenistische - römische Zeit), der ein Buch mit dem Titel $\pi \varepsilon \rho i ~ \Phi \alpha \sigma \eta ́ \lambda ı \delta \alpha$ schrieb (FGrHist 771 F1). Man denkt, dass er ein Bürger von Phaselis wäre (vgl. LPGN VB 52 s.v.

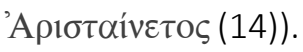

Zwei Bürgern von Phaselis heisst man mit diesem Name. Erster war der Vater des Philosoph Theodektes, der im IV. Jhdt. v. Chr. lebte (TrGF I 227; vgl. Plut. Mor. 478 b). Zweiter kommt auf eine Münze (ca. 250-220 v. Chr.) vor (Heipp-Tamer 1993, 134 no: 87 taf. 5).

Der Name kommt auf den Münzen (ca. 250-220 v. Chr.) vor (HeippTamer 1993, 137 no: 127-130 taf. 7).

Der Name ist in einer Grabinschrift (Kaiserzeit) in Phaselis genannt (SEG

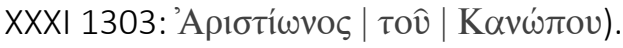

Der Name kommt auf den Münzen (ca. 250-220 v. Chr.) vor (HeippTamer 1993, 137 f. no: 131-133 taf. 7).

Der Name wird in einer Inschrift (I. Jhdt. v. Chr.) aus Rhodos erwähnt

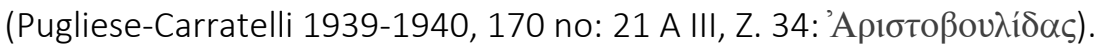

Der Name wird in einer Weihinschrift an Hestia und Hermes aus dem IV. 


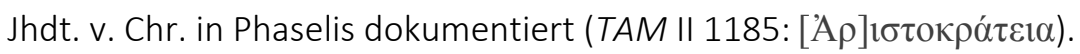

23- 'Aрıбтóviкоs (2): Der Name wird in den zwei Agoninschriften aus der Kaiserzeit in Phaselis

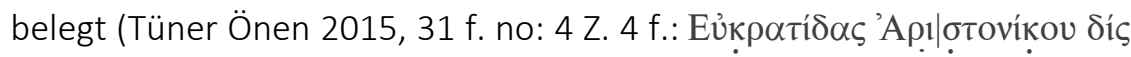
und Adak et al. 2006, 6 f. no: 4 (für die neue Lesung von dem Namen vgl.

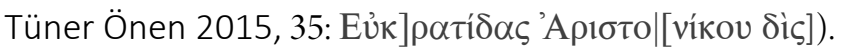

24- 'Apí $\sigma \omega v(3)$ :

Diese Name wird für drei Bürgern von Phaselis bezeugt:

1-2) Beide liegen auf der zwei Münzen mit verschiedenen Daten vor: $c a$. 250-220 v. Chr. (Heipp-Tamer 1993, 135 no: 101 taf. 6); ca. 167-130 v. Chr. (Heipp-Tamer 1993, 157 no: 334 taf. 26).

3) Dritter erscheint in einem Proxenie-Dekret (ca. 240-215 v. Chr.) aus

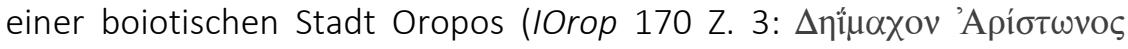
$\Phi \alpha \sigma \eta \mid[\lambda i] \tau \eta v)$.

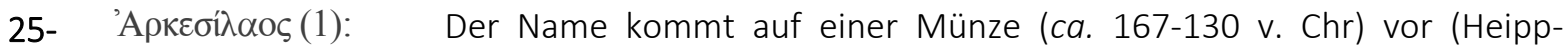
Tamer 1993, 156 no: 325 taf. 26).

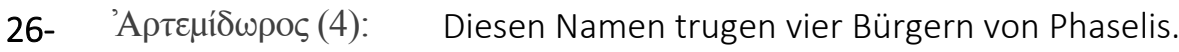

1) Erster wird in einer Grabinschrift aus Rhodos belegt (IG XII. 1 no: 317:

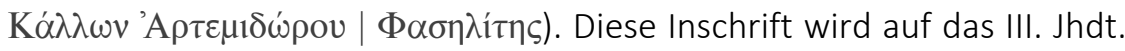
v. Chr. datiert (vgl. Frase 1977, 160 Anm. 403).

2) Zweiter erscheint in einem Proxenie-Dekret (ca. 266 v. Chr.) aus einer

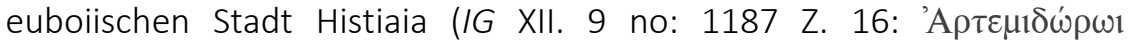

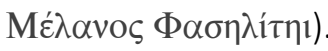

3) Dritter kommt auf einer Münze (ca. 167-130 v. Chr) vor (Heipp-Tamer 1993, 160 no: 372 taf. 29).

4) Letzter ist in einer agonistischen Inschrift (III. Jhdt. n. Chr.) in Phaselis

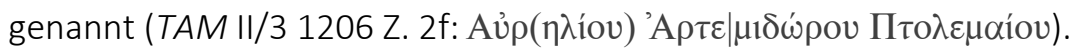

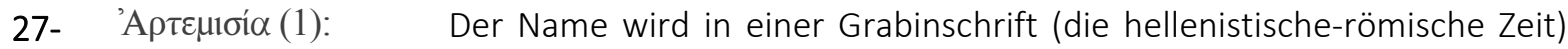

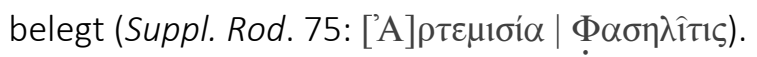

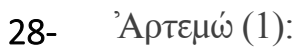

Der Name wird in einer Grabinschrift (I. Jhdt. v. Chr.) erwähnt (IG XII 1

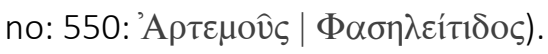

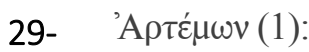

Der Name wird für Händler von Phaselis bezeugt, der im IV. Jhdt. v. Chr. lebte (Demosth., Contr. Lacr.XXXV. 3 ff.; 7; 10; 12; 14 ff.; 30).

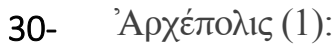

Der Name wird in einer Proxenie-Dekret (322-306 v. Chr.) aus Samos

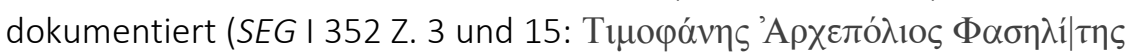

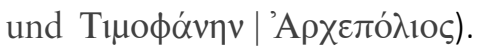

31- 'Архиллоц (1): Der Name kommt auf einer Münze (ca. 167-130 v. Chr.) vor (HeippTamer 1993, 160 no: 374 taf. 29).

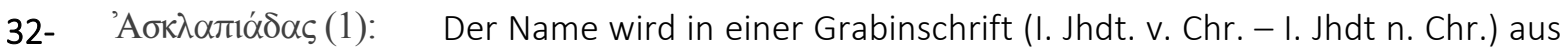

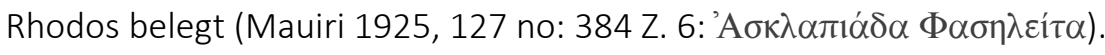

33- 'A $\sigma \kappa \lambda \alpha \pi \dot{\alpha} \varsigma$ (1): Der Name ist in einer Grabinschrift (II-I. Jhdt. V. Chr.) aus Rhodos 


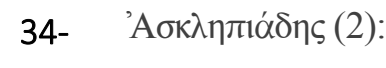

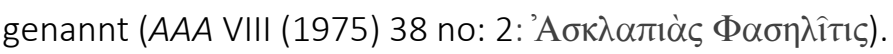

Der Name wird zweimal dokumentiert. Erster liegt als Spender in einer Inschrift (ca. 175-170 v. Chr) aus der karischen Stadt lasos vor (Ilasos 175

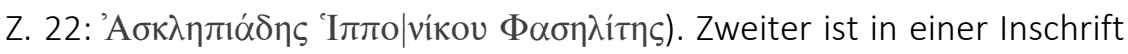

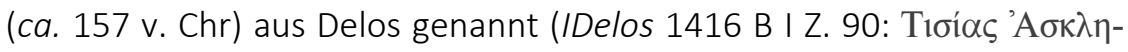

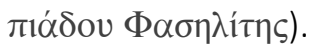

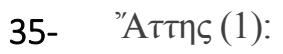

Diesen Namen bezeugt eine Grabinschrift (II.-III. Jhdt. n. Chr.) aus Yarbaşçandır innerhalb des Territoriums von Phaselis (SEG LI 1829 Z. 2:

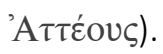

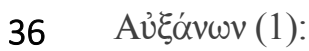

Der Name wird in einer Grabinschrift (II.-III. Jhdt. n. Chr.) in Phaselis belegt (TAM II/3 1217 Z. 3: Aủ Ǵávotı).

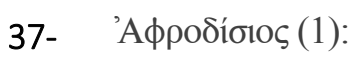

Der Name ist in einer Grabinschrift (II.-I. Jhdt. v. Chr.) aus Rhodos

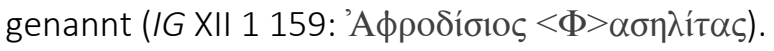

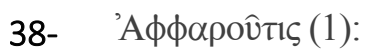

Der Name wird in einer Grabinschrift (III. Jhdt. n. Chr.) aus dem Territorium von Phaselis erwähnt (TAM II/3 1212 Z. 4: 'Aфф $\alpha \rho 0 \hat{\tau} \tau<1>$ ).

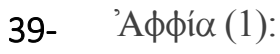

Der Name liegt auf den zwei Inschriften (III. Jhdt. n. Chr.) in Phaselis vor

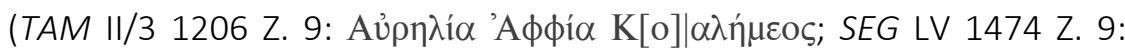

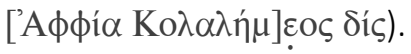

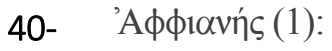

Der Name wird in einer Grabinschrift (III. Jhdt. n. Chr.) aus dem Territorium von Phaselis belegt (TAM II/3 1212 Z. 5: 'A $\phi \phi 1[\alpha v \hat{n}])$.

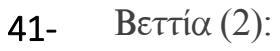

Der Name wird für zwei verschiedene Personen - die Mama und die Tochter- auf einer Inschrift (III. Jhdt. n. Chr.) aus Phaselis dokumentiert

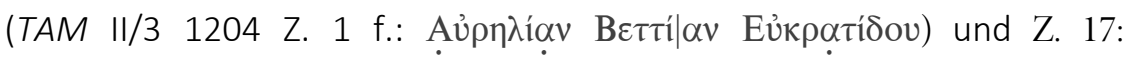

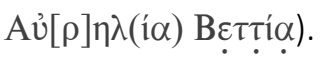

42- Гóïos (1)

Der Name ist in einer Weihinschrift aus der Kaiserzeit in Havuzönüdamı

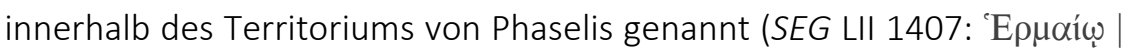
Toî́ov).

43- $\quad \Gamma \eta(1)$ :

Der Name wird in einer Grabinschrift aus der Kaiserzeit in Fillara innerhalb des Territoriums von Phaselis erwähnt (SEG LII 1413 Z. 5: juvaıki $\alpha \dot{u} \tau o \hat{v} \mid \Gamma[\hat{n})$.

44- $\quad \Delta \alpha \lambda \operatorname{lo\sigma } \alpha \lambda \lambda \operatorname{oc}(1)$ : Der Name wird in einer Weihinschrift (II.-I. Jhdt. v. Chr.) aus Mnara innerhalb des Territoriums von Phaselis belegt (Şahin-Adak 2013, 300: $\Delta \alpha v \tau 1 \delta \alpha \rho 1 \varsigma \Delta \alpha \lambda 10 \sigma \alpha \lambda \lambda$ ov).

45- $\quad \Delta \alpha \mu \alpha ́ \alpha \alpha \tau o \varsigma(1): \quad$ Der Name kommt auf einer Münze (ca. 250-220 v. Chr.) vor (HeippTamer 1993, 140 no: 159d).

46- $\quad \Delta \alpha \mu \varepsilon \dot{\alpha}(1)$ :

Der Name kommt auf einer Münze (ca. 167-130 v. Chr.) vor (HeippTamer 1993, 175 no: 4).

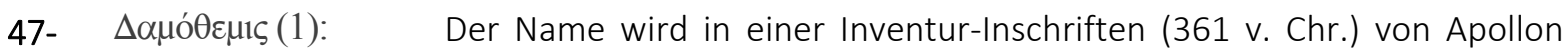

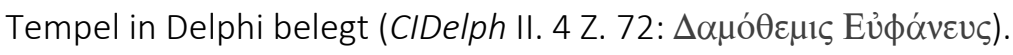

48- $\quad \Delta \alpha \mu \circ \kappa \hat{\eta} \varsigma(1):$ Der Name kommt auf einer Münze (ca. 250-220 v. Chr.) vor (Heipp- 
Tamer 1993, 139 no: 147 taf. 8).

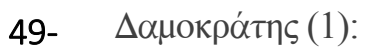

Der Name wird in einer Grabinschrift (die spätklassische - frühhellenisti-

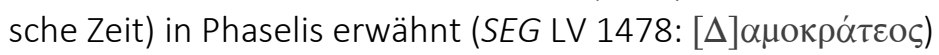

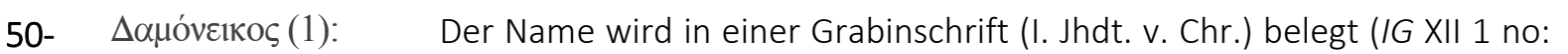
550: $\Delta \alpha \mu$ oveíkou | $\Phi \alpha \sigma \eta \lambda \varepsilon i ́ \tau \alpha)$

51- $\Delta \alpha \mu o ́ \xi \varepsilon v o \varsigma$ (1): $\quad$ Der Name kommt auf einer Münze (ca. 167-130 v. Chr.) vor (HeippTamer 1993, 160 no: 373 taf. 29).

52- $\quad \Delta \alpha \mu o ́ \phi i \lambda o \varsigma(1): \quad$ Der Name kommt auf einer Münze (ca. 250-220 v. Chr.) vor (HeippTamer 1993, 139 no: 143 taf. 8).

53- $\quad \Delta \alpha v \pi \mid \delta \alpha \rho ı$ (1): $\quad$ Der Name wird in einer Weihinschrift (II.-I. Jhdt. v. Chr.) aus Mnara innerhalb des Territoriums von Phaselis dokumentiert (Şahin-Adak 2013,

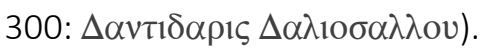

54- $\quad \Delta \varepsilon \dot{v} \alpha \rho \chi о \zeta(1): \quad$ Der Name liegt auf einer Grabinschrift (die hellenistische Zeit?) aus

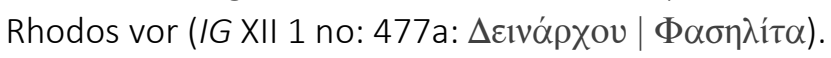

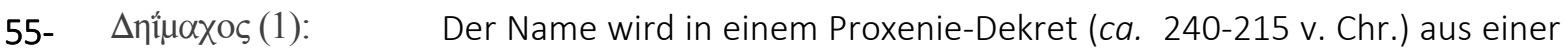

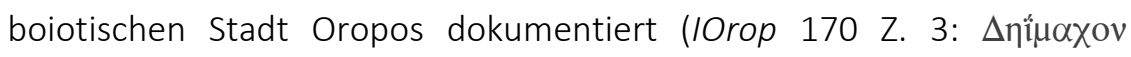

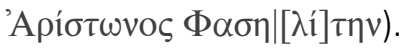

56- $\quad \Delta \varepsilon \mu \varepsilon \tau \rho i ́ \alpha(1): \quad$ Diesen Namen bezeugt eine Grabinschrift aus der Kaiserzeit in Phaselis (TAM II/3 1210 Z. 4 f.: $\Delta \varepsilon \mid[\mu] \varepsilon \tau$ pí $\alpha$ ).

57- $\quad \Delta \eta \mu \eta \tau$ ті́ (1): $\quad$ Der Name wird in einer Grabinschrift aus der Kaiserzeit in Kocaköy innerhalb des Territoriums von Phaselis erwähnt (Ormerod - Robinson 1914, 32 no: 48 Z. 6: $\Delta \eta \mu \eta \tau \rho i ́ ⿱ \alpha . ~ K \alpha \rho \pi о \widehat{)})$.

58- $\quad \Delta \eta \mu \hat{n} \operatorname{pos}(1)$ : $\quad$ Der Name wird in einer Inschrift (I. Jhdt. v. Chr) aus Rhodos belegt

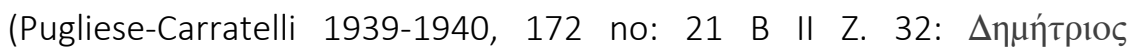
$\Phi \alpha \sigma \eta \lambda \varepsilon i \tau \alpha \varsigma)$.

59- $\Delta 1 \delta \omega v(1)$ :

Der Name liegt auf einer Grabinschrift aus der Kaiserzeit in Armutçuk innerhalb des Territoriums von Phaselis vor (SEG LII 1412: Kouyas $\Delta \mathrm{l} \delta \omega[\operatorname{voc}])$.

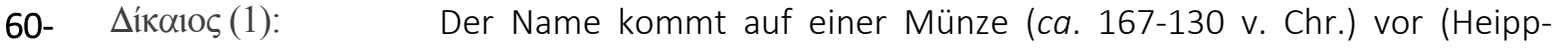
Tamer 1993, 157 no: 340, taf. 27).

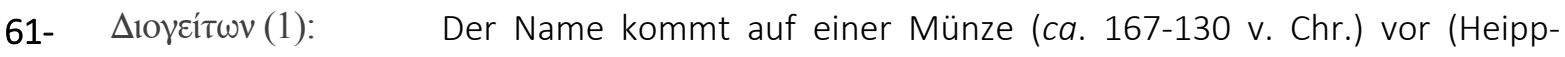
Tamer 1993, 156 no: 330, taf. 26).

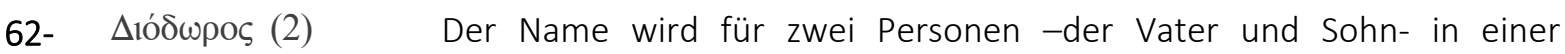
Siegerliste (ca. 65-60 v. Chr.) aus einer Boiotischen Stadt Thespiai belegt

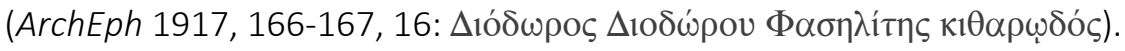

63- $\Delta \operatorname{lovú\sigma ıo\zeta ~(3):~} \quad$ Drei Personen von Phaselis trugen den Namen:

1) Erster war ein Grammatiker von der hellenistischen Zeit (Sch. Pind. vol. 1 X. 55; vol. 2 II. 43 ff.; vol. 3 Xla. 17-23; Schol. Nic. 1-6).

2-3) Die letzten Beiden kommen auf den Münzen vor (Heipp-Tamer 1993, 138 no: 136 taf. 8 (ca. 250-220 Jhdt. v. Chr.) und 158 no: 355 taf. 
28 (ca. 167-130 Jhdt. v. Chr.).

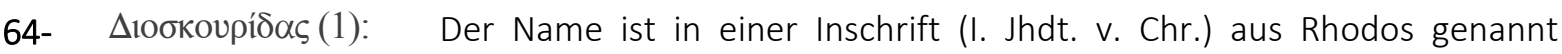

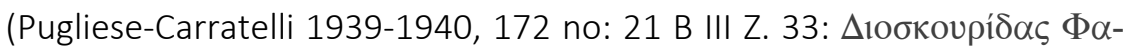
$\sigma \eta \lambda \varepsilon i ́ \tau \alpha \varsigma)$.

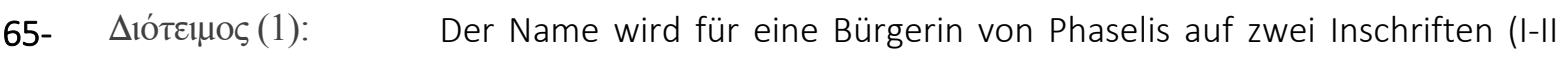

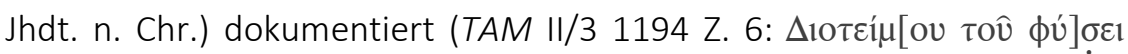

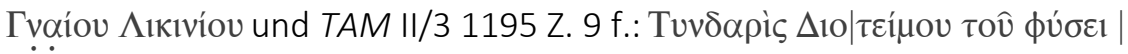

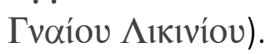

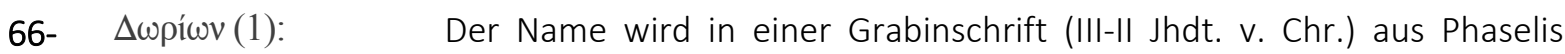

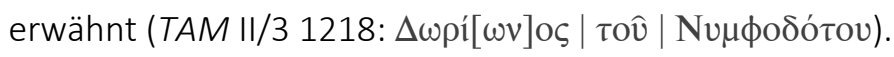

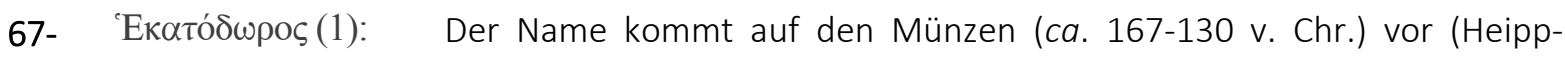
Tamer 1993, 157 no: 332, taf. 28).

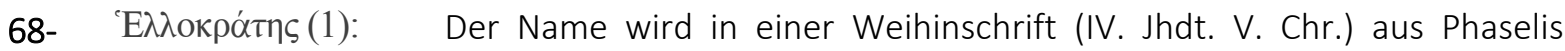

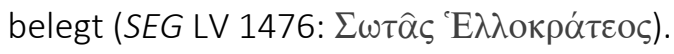

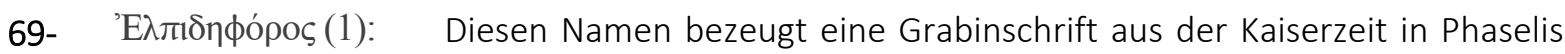

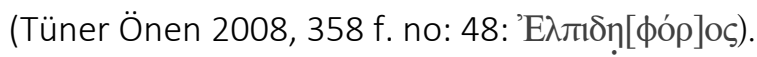

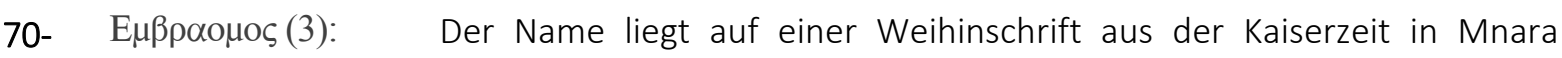

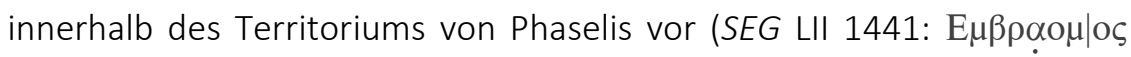

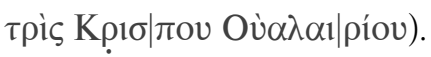

71- "Ецßроно (3): Der Name wird dreimal belegt:

1-2) Die ersten Beiden erscheinen auf den zwei Agoninschriften (II. Jhdt.

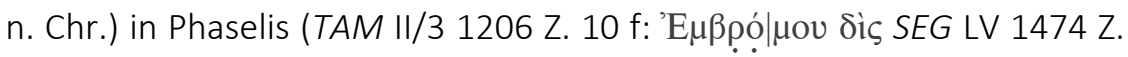

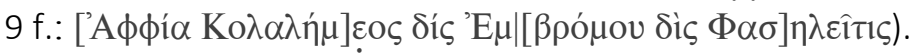

3) Dritter liegt auf einer Weihinschrift (II.-I. Jhdt. v. Chr.) aus Mnara innerhalb des Territoriums von Phaselis vor (Şahin-Adak 2013, 300: Eußpouov).

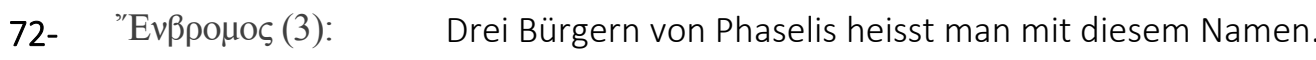

1-2) Die ersten Beiden sind in einer Ehreninschrift aus der Kaiserzeit in

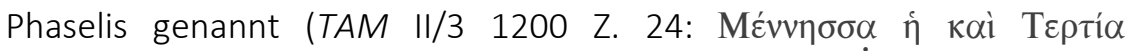

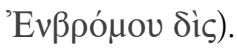

3) Dritter liegt auf einer Grabinschrift aus der Kaiserzeit in Phaselis vor

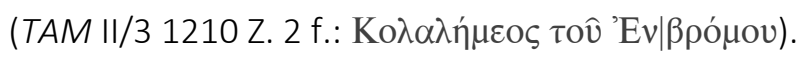

73- 'Eлıх́́рпৎ (1): Der Name kommt auf einer Münze (ca. 167-130 v. Chr.) vor (HeippTamer 1993, 156 no: 328, taf. 26).

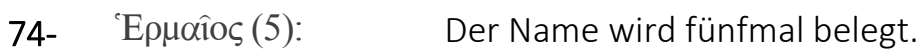

1) In einer Weihinschrift aus der Kaiserzeit in Havuzönüdamı innerhalb

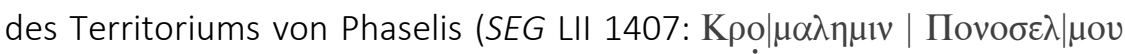

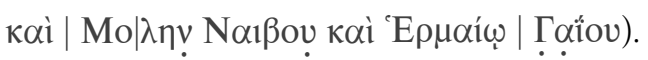

2-3) In einer Grabinschrift aus der Kaiserzeit in Kocaköy innerhalb des 
Territoriums von Phaselis (Ormerod - Robinson 1914, 32 no: 48:

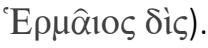

4-5) In den zwei Weihinschriften aus der Kaiserzeit in Mnara innerhalb

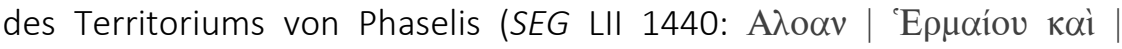

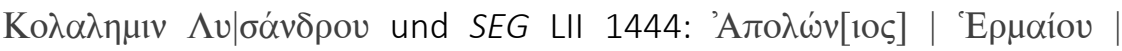

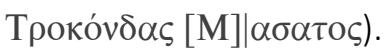

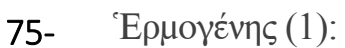

Der Name wird in den zwei Ehreninschriften (ca. 120 v. Chr.) aus Rhodos dokumentiert (Pugliese-Carratelli 1939-1940, 156-158 no: 18 B Z. 1

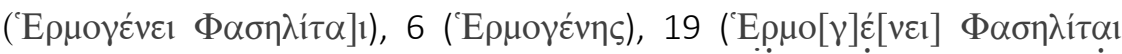

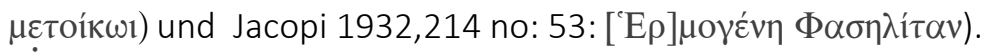

76- 'Epunveús (1): Der Name kommt auf einer Münze (ca. 167-130 v. Chr.) vor (HeippTamer 1993, 156 no: 326, taf. 26)

77- Eủios (1):

Der Name kommt auf den Münzen (ca. 250-220 v. Chr.) vor (HeippTamer 1993, 135 no: 98-99, taf. 5)

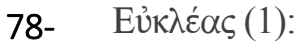

Der Name kommt auf den Münzen (ca. 250-220 v. Chr.) vor (HeippTamer 1993, 138 no: 140-142, taf. 8)

79- $\quad$ EỦं $\lambda \varepsilon 1 \alpha(1)$ :

Der Name erscheint in einer Grabinschrift (I. Jhdt. v. Chr. - I. Jhdt. n.

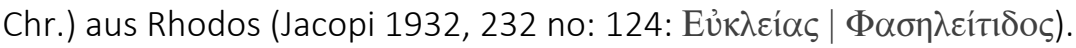

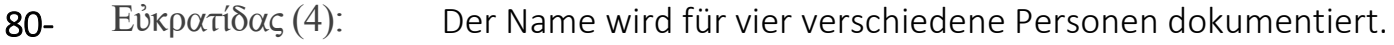

1) Auf den Münzen (ca. 250-220 v. Chr.) (Heipp-Tamer 1993, 139 no: 149-154, taf. 8).

2) In einer Ehreninschrift aus der Kaiserzeit in Phaselis (TAM II/3 1204

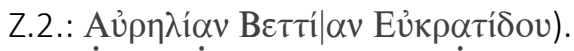

3-4) In den vier Agoninschriften aus der Kaiserzeit in Phaselis (erste:

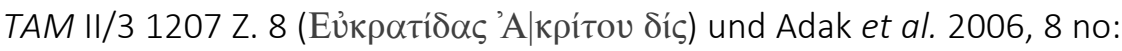

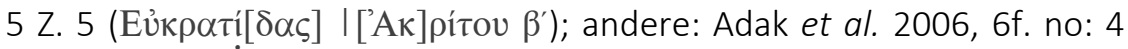
(für die neue Lesung von dem Namen vgl. Tüner Önen 2015, 31 f. no: 4

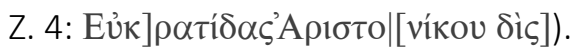

81- Eủktńluvv (1): Der Name kommt auf einem Graffiti aus der hellenistischen Zeit aus

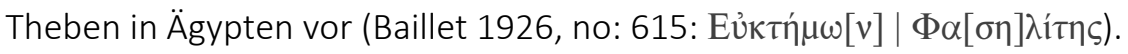

82- Eûvic (1): Der Name erscheint auf einer Grabinschrift (hell.-röm. Zeit) aus

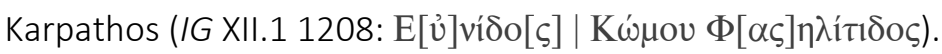

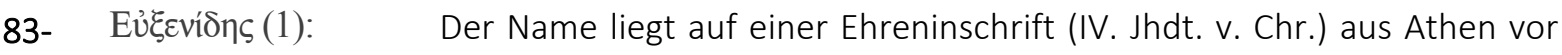

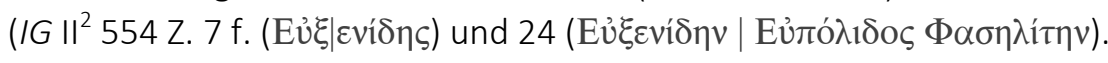

84- Eứroגıs (1): Diesen Namen bezeugt eine Ehreninschrift (IV. Jhdt. v. Chr.) aus Athen

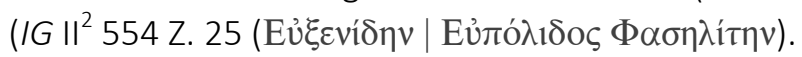

85- Eủpúßıৎ (1): Der Name kommt auf einer Münze (ca. 167-130 v. Chr.) vor (HeippTamer 1993, 156 no: 327 taf. 26)

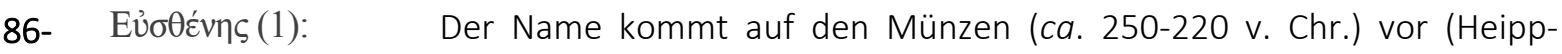


87- Eủtuxńs (2):

88- Eủtuxlavós (1):

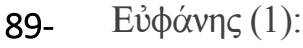

90- Znvíketᄁৎ (3):

91- Znvíivv (1):

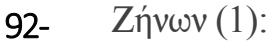

93- Z Z

94- Zwбínos (1):

95- '

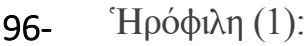

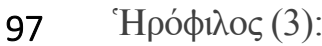

98- $\quad{ }^{~} \mathrm{H} \rho \omega \mathrm{\delta} \delta \alpha \varsigma$ (1):

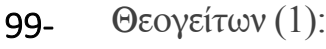

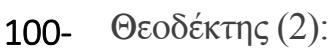

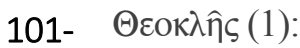

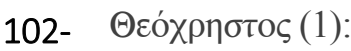

Tamer 1993, 138 no: 134-138, taf. 7f.).

Der Name wird in zwei Grabinschriften aus der Kaiserzeit belegt. Eine von diesen Inschriften ist aus Phaselis (Blackman 1981, 147 f. no: 7 Z. 2: Eủiuxńs); andere ist aus Zindanyakası innerhalb des Territoriums von

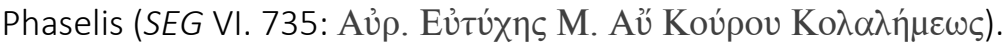

Der Name wird in einer Grabinschrift aus der Kaiserzeit in Phaselis belegt

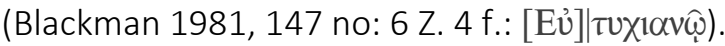

Der Name wird in einer Inventur-Inschrift (361 v. Chr.) von Apollon

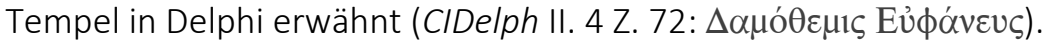

Der Name wird für drei verschiedene Personen - der Sohn, der Vater und der Grossvater- in einer Ehreninschrift (III. Jhdt. n. Chr.) in Phaselis

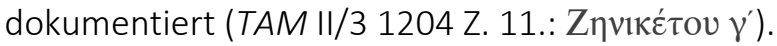

Der Name kommt auf einer Münze (ca. 167-130 v. Chr.) vor (HeippTamer 1993, 159 no: 361 taf. 29).

Der Name wird in einer Inschrift aus der Kaiserzeit (?) in Phaselis erwähnt (TAM II/3 1208: Zńvwvi).

Der Name wird in einer Agoninschrift (III. Jhdt. n. Chr.) in Phaselis belegt

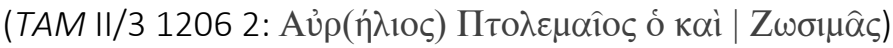

Der Name liegt auf der Mozaikinschrift (III. Jhdt. n. Chr.?) von Palästra in

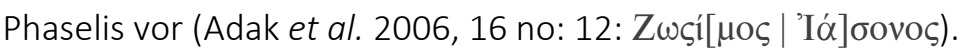

Diesen Namen bezeugt eine Ehreninschrift aus der hellenistischer Zeit

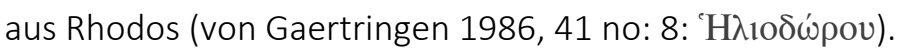

Der Name wird in einer Grabinschrift aus der Kaiserzeit in Phaselis dokumentiert (Blackman 1981, 149 no: 9 Z. 6: 'Hрoфínn).

Der Name wird für zwei Personen -der Vater und der Sohn- in einer Grabinschrift aus der Kaiserzeit in Phaselis (Blackman 1981, 149 no: 9 Z.

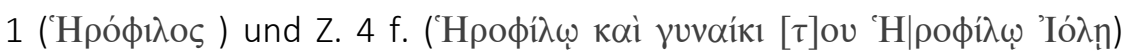
und in einer Ehreninschrift (II-III. Jhdt. n. Chr.) in Phaselis belegt (Tüner

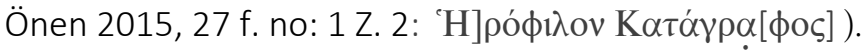

Der Name kommt auf einer Münze (ca. 167-130 v. Chr.) vor (HeippTamer 1993, 156 no: 331 taf. 26).

Der Name kommt auf einer Münze (ca. 167-130 v. Chr.) vor (HeippTamer 1993, 157 no: 339 taf. 27).

Zwei Bürgern von Phaselis mit diesem Namen sind bekannt. Erster ist der Philosoph Theodektes, der im IV. Jhdt. v. Chr. lebte (TrGF I 227; vgl. Plut. Mor. 478 b); zweiter ist der Sohn des Theodektes (TrGFI 72 T 1).

Der Name kommt auf einer Münze (ca. 250-220 v. Chr.) vor (HeippTamer 1993, 140 no: 159b taf. 9).

Der Name kommt auf einer Münze (ca. 167-130 v. Chr.) vor (HeippTamer 1993, 159 no: 368 taf. 29). 
103- - $\Theta \varepsilon \sigma \tau o p ı \delta \alpha \varsigma ~(1): \quad$ Der Name ist in einer Grabinschrift aus der hellenistischer Zeit (?) aus

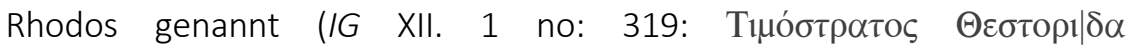
$<\Phi>\alpha \varsigma<\eta>\lambda<i>\tau \alpha[\varsigma])$.

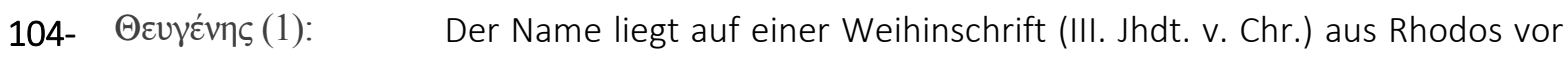
(IG XII. 1 no: 112: $\Theta \varepsilon v[\gamma] \varepsilon ́ v \eta \varsigma ~ \Phi \alpha \sigma \eta \lambda[i ́ \tau] \alpha \varsigma)$.

105- $\Theta \varepsilon v \delta \dot{\omega} \rho \alpha(1)$ : Der Name erscheint in einer Grabinschrift (hell.-röm.) aus Rhodos

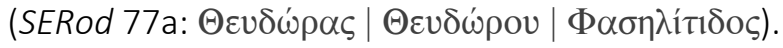

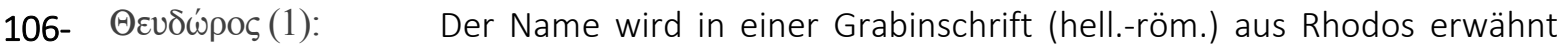

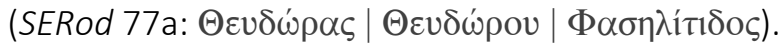

107- 'Ióowv (1):

Der Name liegt auf der Mozaikinschrift (III. Jhdt. n. Chr.?) von Palästra in

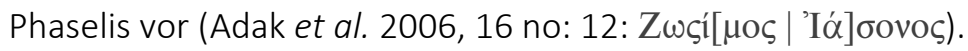

108 ' $\mathrm{I} \alpha \tau \rho \kappa \lambda \hat{\eta} \varsigma(1):$

Der Name erscheint in einer Grabinschrift (450-425 v. Chr.) aus Athen

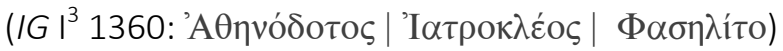

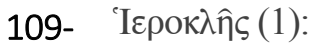

110- ' 'ó̀n (1):

Der Name wird in den Inventur-Inschriften von Athena Tempel in Athen, die zwischen die Jahren $400-390 \mathrm{v}$. Chr datiert werden, belegt $\left(I G \|^{2}\right.$ no:

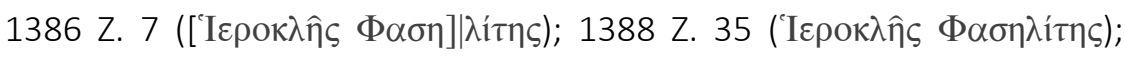

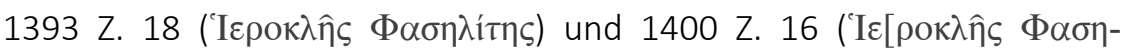
$\lambda i$ ínद])).

Der Name wird in einer Grabinschrift aus der Kaiserzeit in Phaselis

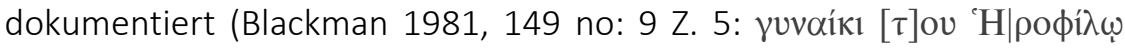
'Ió̀n)).

111- 'Iлтóvikos (1): Der Name liegt auf einer Inschrift (ca. 175-170 v. Chr) aus der karischen

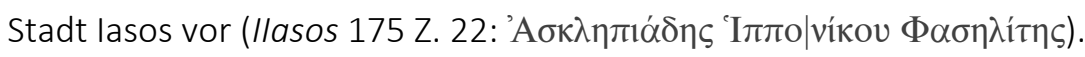

112 'Iøı⿻่v' (1):

Diesen Namen bezeugt eine Grabinschrift (II. Jhdt. v. Chr.) aus Rhodos

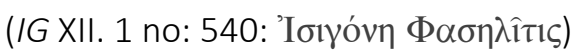

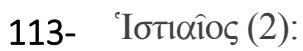

114- Kód $\lambda \omega \omega v(1):$

Der Name wird für zwei Personen belegt. Erster liegt auf einer Inschrift

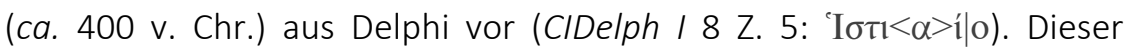
Bürger von Phaselis wurde als theoros nach Delphi gesandt. Zweiter kommt auf einer Münze (ca. 167-130 v. Chr.) vor (Heipp-Tamer 1993, 157 no: 341 taf. 27).

Der Name wird in einer Grabinschrift aus Rhodos erwähnt (IG XII.1 no:

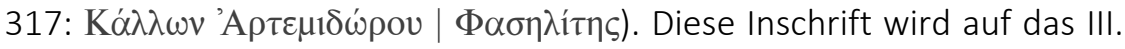
Jhdt. v. Chr. datiert (vgl. Frase 1977, 160 Anm. 403).

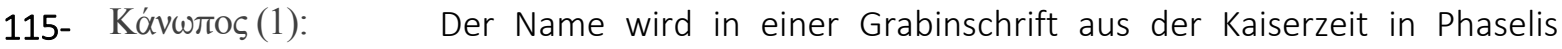

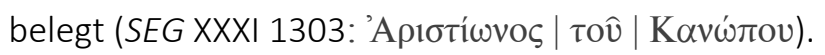

116- К Карто́ (1):

Der Name wird in einer Grabinschrift aus der Kaiserzeit in Kocaköy innerhalb des Territoriums von Phaselis dokumentiert (Ormerod -

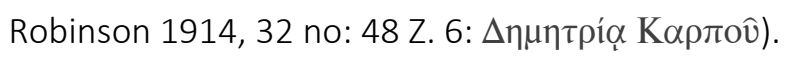

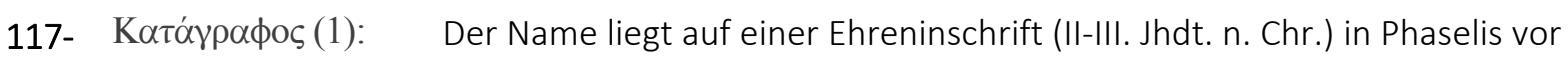

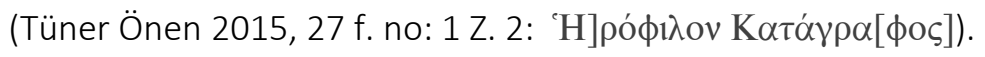




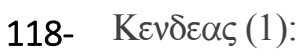

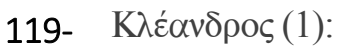

120- K入Eivías (1):

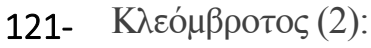

122- K K $1 \dot{\omega}(1)$ :

123- K K $\varepsilon_{\omega v}(1)$ :

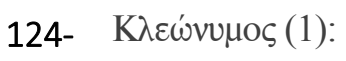

125- Kóìvos (1):

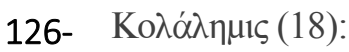

Der Name wird in einer Grabinschrift (II-III Jhdt. n. Chr.) aus Incircik innerhalb des Territoriums von Phaselis erwähnt (SEG VI. 734: M.

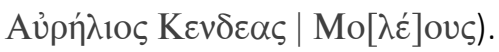

Der Name ist in einer Weihinschrift (IV. Jhdt. v. Chr.) in Phaselis genannt

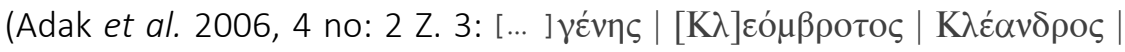

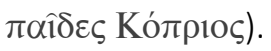

Der Name kommt auf den Münzen (ca. 250-220 v. Chr.) vor (HeippTamer 1993, 135 no: 104-105 taf. 6).

Der Name wird für zwei Personen belegt. Erster liegt auf einer Weihinschrift (IV. Jhdt. v. Chr.) in Phaselis vor (Adak et al. 2006, 4 no: 2 Z.

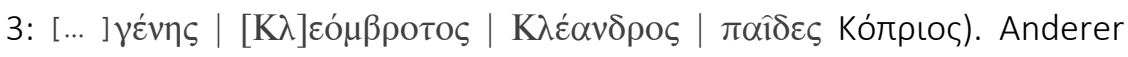
kommt auf den Münzen (ca. 250-220 v. Chr.) vor (Heipp-Tamer 1993, 135 no: 95-96 taf. 5).

Der Name wird in einer Inschrift (I. Jhdt. v. Chr.) aus Rhodos dokumen-

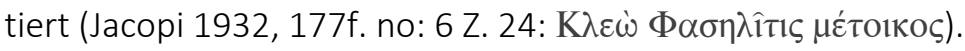

Der Name kommt auf einer Münze (ca. 167-130 v. Chr.) vor (HeippTamer 1993, 156 no: 323 taf. 25).

Der Name kommt auf einer Münze (ca. 167-130 v. Chr.) vor (HeippTamer 1993, 159 no: 369 taf. 29).

Diesen Namen bezeugt eine Weihinschrift aus der Kaiserzeit in Havuzönüdamı innerhalb des Territoriums von Phaselis (SEG LII 1405: Kóövtos).

Bislang werden 18 Personen bestimmt, die den Namen Kolalemis trugen. Der Name wird nur in Phaselis (13 Personen) und ihrem Territorium (5 Personen) belegt:

1) In einer Ehreninschrift aus der Kaiserzeit in Phaselis (TAM I//3 $1200 \mathrm{Z.}$

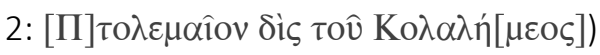

2-7) In einer Ehreninschrift (II. Jhdt. n. Chr.) aus Phaselis für die sechs verschieden Personen - Sechs Generationen- (TAM II/3 1202 Z. 4 und

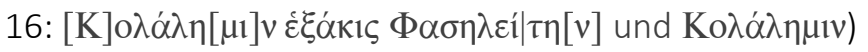

8-9) In einer Ehreninschrift (III. Jhdt. n. Chr.) aus dem Phaselis für zwei verschiedene Personen -der Sohn und der Vater- (TAM II/ 31204 Z. 18

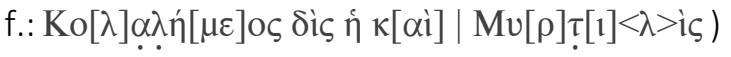

10-11) In einer Agoninschriften (III. Jhdt. n. Chr.) aus dem Phaselis für zwei verschiedene Personen -der Vater und der Sohn- (TAM II/3 12069 f.: $\left.\mathrm{K}[\mathrm{o}] \mid \lambda \alpha \lambda \dot{n} \mu \varepsilon \varsigma_{\varsigma} \delta \dot{i} \varsigma\right)$

12) In den zwei Agoninschriften (III. Jhdt. n. Chr.) in Phaselis (TAM II/3

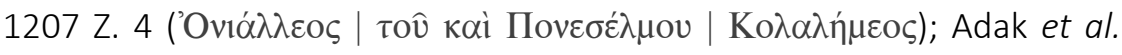

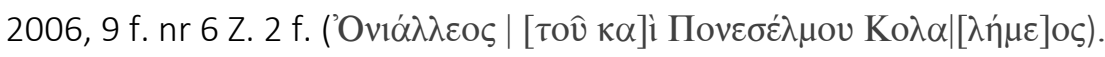

13) In einer Grabinschrift aus der Kaiserzeit in Phaselis (TAM II/3 $1210 \mathrm{Z}$.

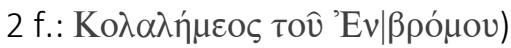


14) In einer Grabinschrift von Kaiserzeit in Zindanyakası innerhalb des Territoriums von Phaselis (SEG VI. 735: Aủp. Eủtúxns M. Aư Koúpov Ko $\lambda \alpha \lambda \eta \dot{\mu} \mu \omega \varsigma)$.

15) In einer Weihinschrift aus der Kaiserzeit in Mnara innerhalb des

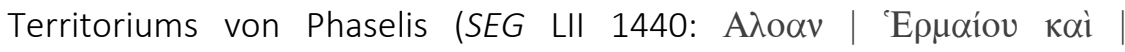
Ko $\lambda \alpha \lambda \eta \mu \nu v \Lambda v \mid \sigma \alpha ́ v \delta \rho \circ o v)$

16-18) In einer Weihinschrift aus der Kaiserzeit in Mnara innerhalb des Territoriums von Phaselis (SEG LII 1442: Ko $\alpha \lambda \eta \eta \mid \mu\left\llcorner\varsigma \gamma^{\prime}\right.$ ).

127- Kóvwv (1):

128- Ко́тріє(1):

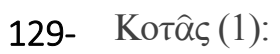

130- Koúyac (3):

131- Kоuктоৎ (1):

132- Koûpos (1):

133- Kpótnৎ (1):

134- Крі́блоц (1):

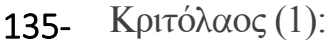

136- Kpıтó
Der Name kommt auf einer Münze (ca. 250-220 v. Chr.) vor (HeippTamer 1993, 135 no: 106, taf. 6).

Der Name wird in einer Weihinschrift (IV. Jhdt. v. Chr.) in Phaselis belegt

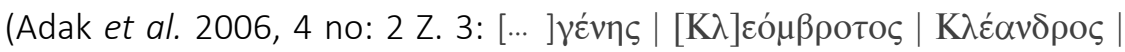

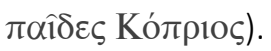

Der Name liegt auf einer Weihinschrift aus der Kaiserzeit in Havuzönüdamı innerhalb des Territoriums von Phaselis vor (SEG LII 1404: M. Aủp. Kotâs).

Der Name wird für drei verschiedene Personen belegt:

1) In den zwei Agoninschriften (III. Jhdt. n. Chr.) in Phaselis (SEG LV

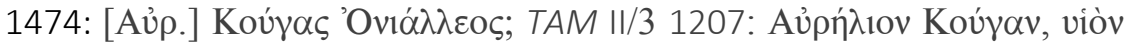

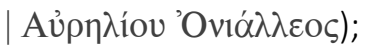

2) In einer Grabinschrift aus der Kaiserzeit in Armutçuk innerhalb des Territoriums von Phaselis (SEG LII 1412: Kouy as $\Delta 1 \delta \omega[v o \varsigma]$ )

3) In einer Weihinschrift aus der Kaiserzeit in Havuzönüdamı innerhalb

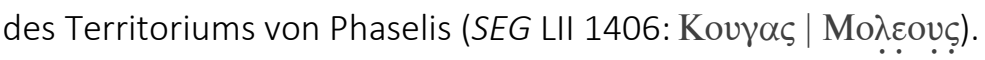

Der Name liegt auf einer Grabinschrift (II.-III. Jhdt. n. Chr.) aus Yarbaşçandır innerhalb des Territoriums von Phaselis vor (SEG LI 1829 Z.

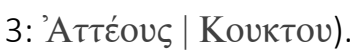

Der Name wird in einer Grabinschrift aus Zindanyakası innerhalb des Territoriums von Phaselis erwähnt (SEG VI. 735: Aủp. Eủtúxns M. Aú. Koúpou Koג $\alpha \lambda \eta \dot{\mu} \mu \varepsilon \omega \varsigma)$. Diese Inschrift wird nach dem Jahr 212 n. Chr. datiert.

Der Name kommt auf einer Münze (ca.167-130 v. Chr.) vor (HeippTamer 1993, 158 no: 356 taf. 28).

Der Name wird in einer Weihinschrift aus der Kaiserzeit in Mnara innerhalb des Territoriums von Phaselis erwähnt (SEG LII 1441:

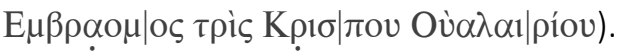

Ein bekannter Mathematiker (II. Jhdt. v. Chr.) aus Phaselis trug den Namen (RE XI 2 s.v. Kritolaos (3), s. 1930 ff.)

Der Name kommt auf den Münzen (ca. 250-220 v. Chr.) vor (HeippTamer 1993, 136 no: 109-111 taf. 6). 


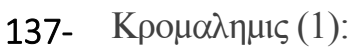

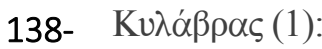

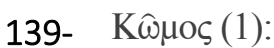

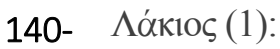

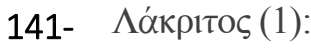

142- $\Lambda \alpha \phi \alpha ́ v \eta \varsigma(1):$

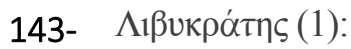

144- $\Lambda$ ípus (1):

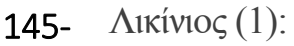

146- $\Lambda u ́ \kappa \omega v(2):$

147- $\Lambda u ́ \sigma \alpha v \delta \rho \circ \varsigma(1):$

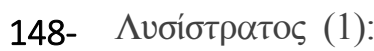

149- $\Lambda$ wióvikos (1):

150- Ма́ркоৎ (1):

151- $M \alpha \sigma \alpha \varsigma(1):$

\section{Nihal TÜNER ÖNEN}

Diesen Namen bezeugt eine Weihinschrift aus der Kaiserzeit in Havuzönüdamı innerhalb des Territoriums von Phaselis (SEG LII 1407:

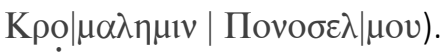

Mythischer Heros von Phaselis, der dem Oikisten Lakios Phaselis gegen Pökelfisch überließ, trug den Namen (FGrHist 448 F1).

Der Name wird in einer Grabinschrift (die hellenistische - römische Zeit)

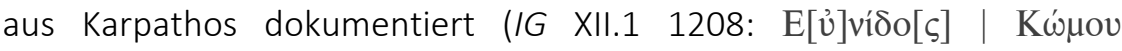
$\Phi[\alpha \varsigma] \eta \lambda i ́ \tau 1 \delta \circ \varsigma)$

Mythischer Gründer von Phaselis trug den Namen (Ael. Herod. Pros. Cath. III. 1. 253; Blinkenberg 1941, 169-171, No: 2).

Der Name wird für einen Händler von Phaselis belegt, der im IV. Jhdt. v. Chr. lebte (Demosth. Contr. Lacr.XXXV).

Der Name ist in einer Siegerliste von Asklepieia im Kos genannt, die in die Zeit zwischen ca. 200 und 168 v. Chr. datiert werden kann (Klee

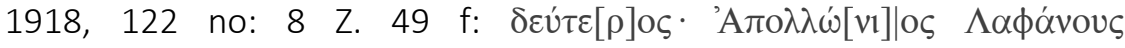
$\Phi \alpha \sigma \eta \lambda i ́ \tau \eta \varsigma)$.

Der Name kommt auf einer Münze (ca. 250-220 v. Chr.) vor (HeippTamer 1993, 135 no: 100, taf. 5).

Der Name kommt auf den Münzen (ca. 250-220 v. Chr.) vor (HeippTamer 1993, 136 no: 113-114 taf.65).

Der Name wird für eine Bürgerin von Phaselis auf zwei Inschriften (I-II

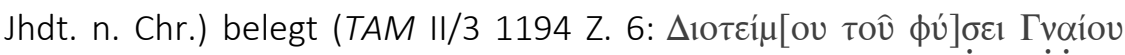

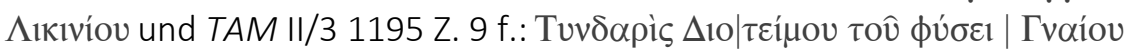

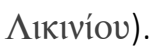

Der Name liegt auf den zwei Graffitis aus der hellenistischen Zeit in

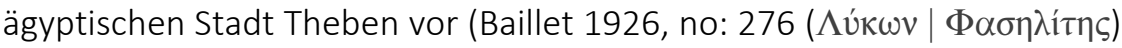
und 1214 ( $\Lambda \dot{[}[\kappa \omega v] \Phi \alpha \sigma \eta \lambda i ́ \tau \varsigma))$.

Der Name erscheint auf einer Weihinschrift aus der Kaiserzeit in Mnara

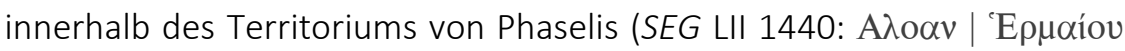

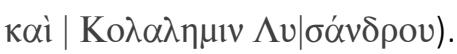

Der Name kommt auf einer Münze (ca. 167-130 v. Chr.) vor (Lanz sale 153 (2011) 288).

Der Name kommt auf einer Münze (ca. 250-220 v. Chr.) vor (HeippTamer 1993, 139 no: 148, taf. 8).

Der Name wird für eine Bürgerin von Phaselis auf zwei Inschriften (I-II

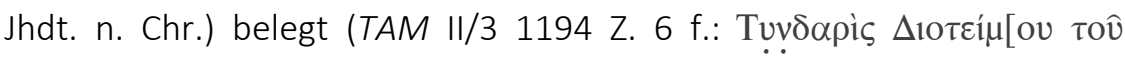

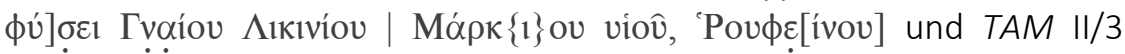

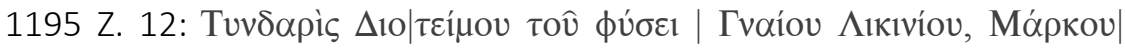
viou, 'Pouфe[ívou]).

Der Name wird in einer Weihinschrift aus der Kaiserzeit in Mnara inner- 


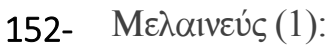

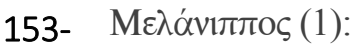

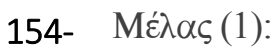

155- Mév

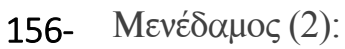

157- Мвvекро́тпৎ (1):

158- Mévๆৎ (1):

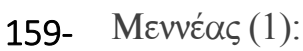

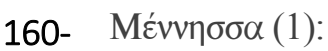

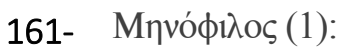

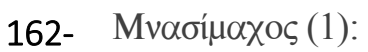

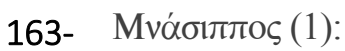

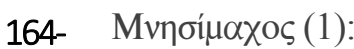

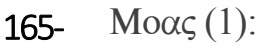

166- Mó̀nฺ (6): halb des Territoriums von Phaselis erwähnt (SEG LII 1444: 'A $\mathrm{A} 0 \lambda \hat{\omega} v[10 \varsigma]$ |

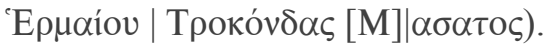

Der Name kommt auf den Münzen (ca.167-130 v. Chr.) vor (HeippTamer 1993, 157 no: 335-336 taf. 26; Lanz Sale 30 (1984) 302).

Der Name wird als der Vatersname des Nestor, der Offizier im ptolemaischen Dienst war, auf einer Weihinschrift (9 Juli 116 v. Chr.) aus einer

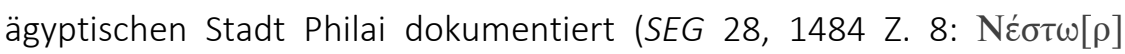

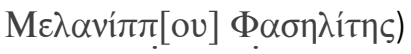

Der Name erscheint auf einem Proxenie-Dekret (ca. 266 v. Chr.) aus

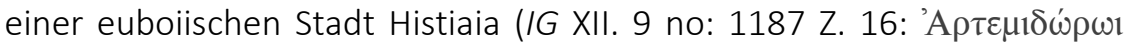

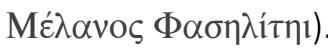

Der Name liegt auf einer Weihinschrift aus der Kaiserzeit in Mnara

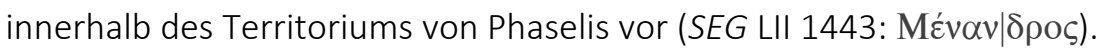

Der Name wird in einer Grabinschrift (II-I. Jhdt. v. Chr.) in Phaselis (Adak

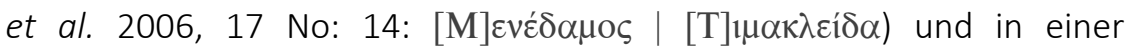
Grabinschrift von der hellenistischen Zeit (?) aus Rhodos erwähnt

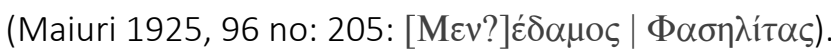

Der Name kommt auf einer Münze (ca.167-130 v. Chr.) vor (HeippTamer 1993, 157 no: 338 taf. 27).

Der Name kommt auf den Münzen (ca. 250-220 v. Chr.) vor (HeippTamer 1993, 137 no: 124-125, taf. 7).

Der Name kommt auf den Münzen (ca. 167-130 v. Chr.) vor (HeippTamer 1993, 157 no: 345 taf. 27; G. Henzen FPL 156 (2005) 209).

Der Name wird in einer Ehreninschrift aus der Kaiserzeit in Phaselis

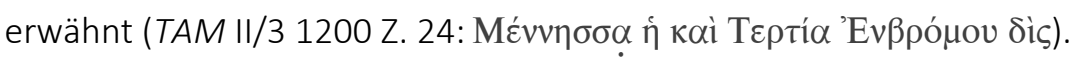

Der Name kommt auf den Münzen (ca.167-130 v. Chr.) vor (HeippTamer 1993, 159 no: 366-367 taf. 29).

Der Name erscheint auf einem Graffiti aus der hellenistischen Zeit aus

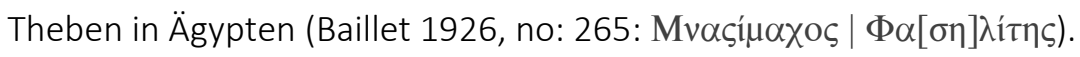

Der Name kommt auf einer Münze (ca.167-130 v. Chr.) vor (HeippTamer 1993, 158 no: 358 taf. 28).

Ein Grammatiker von Phaselis (IV/III. Jhdt. v. Chr.) trug den Namen (FGrHist 841).

Der Name liegt auf einer Weihinschrift aus der Kaiserzeit in Havuzönüdamı innerhalb des Territoriums von Phaselis vor (SEG LIII 1642: Modṣ).

Der Name wird für sechs verschiedene Personen dokumentiert:

1) In einer Grabinschrift aus der Kaiserzeit in Phaselis (TAM II/3 1210:

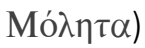

2) In einer Grabinschrift (III. Jhdt. n. Chr.) aus dem Territorium von 


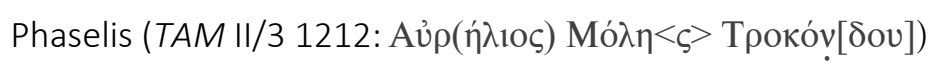

3-4) In den zwei Weihinschriften aus der Kaiserzeit in Havuzönüdamı

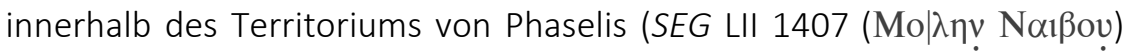
und (SEG LII 1406: Kouyas | Moגعoụ)).

5) In einer Grabinschrift aus der Kaiserzeit in Kocaköy innerhalb des Territoriums von Phaselis (Ormerod - Robinson 1914, 32 no: 48:

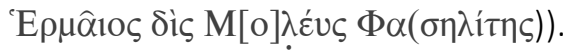

6) In einer Grabinschrift (II-III Jhdt. n. Chr.) aus İncircik innerhalb des

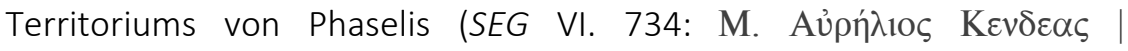
$\left.\mathrm{Mo}\left[\lambda \varepsilon^{\prime}\right] \mathrm{ou \varsigma}\right)$.

167- Mooxíwv (1):

Diesen Namen bezeugt eine Ehreninschrift (II-I. Jhdt. v. Chr.) aus Rhodos

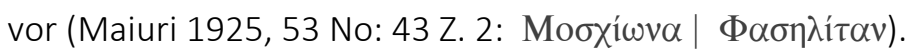

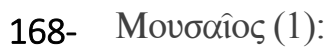

Der Name erscheint in einer Inschrift (316-309 v. Chr.) aus Athen, die

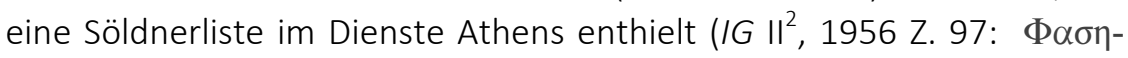

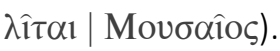

169- $\operatorname{Mv\rho \mu \lambda \alpha /}$

Múpı $\lambda \lambda \alpha(1)$ :

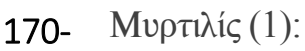

171- $\operatorname{N\alpha } \beta 0 \zeta(1)$

172- Naìs (2):

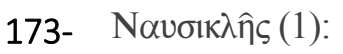

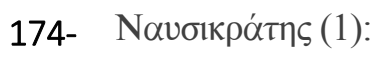

175- Navoívikos (1):

176- $\quad \mathrm{N} \varepsilon \mu \beta \mu о \varsigma(1):$

177- N N

178- Néwv (1):
Der Name liegt auf einer Grabinschrift (II.-III. Jhdt. n. Chr.) aus Yarbaşçandır innerhalb des Territoriums von Phaselis vor (SEG LI 1829 :

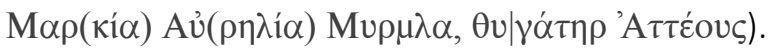

Der Name wird als der Beiname von Kolalemis auf einer Ehreninschrift (III. Jhdt. n. Chr.) in Phaselis dokumentiert (TAM II/ 31204 Z. 18 f.: $\mathrm{Ko}[\lambda] \alpha \lambda \dot{n}[\mu \varepsilon] \mathrm{s} \varsigma \mathrm{\delta i \varsigma} \dot{\eta} \kappa[\alpha i] \mid \mathrm{Mv}[\rho] \tau[1]<\lambda>i \varsigma)$.

Der Name erscheint auf einer Weihinschrift aus der Kaiserzeit in Havuzönüdamı innerhalb des Territoriums von Phaselis (SEG LII 1407:

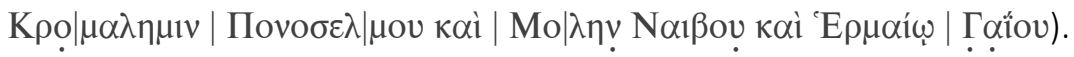

Der Name wird in den zwei Grabinschriften aus Phaselis belegt (Tüner

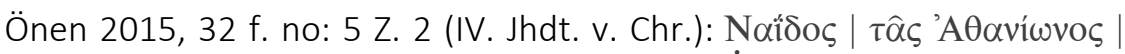

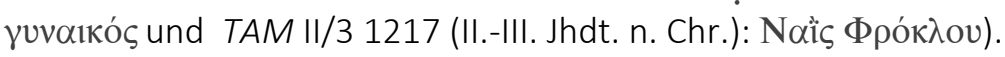

Der Name kommt auf einer Münze (ca. 250-220 v. Chr.) vor (HeippTamer 1993, 140 no: 155 taf. 9).

Der Name kommt auf einer Münze (ca. 250-220 v. Chr.) vor (HeippTamer 1993, 140 no: 159a, taf. 9).

Der Name kommt auf den Münzen (ca. 250-220 v. Chr.) vor (HeippTamer 1993, 134 no: 88-89 taf. 5).

Der Name wird in einer Weihinschrift aus der Kaiserzeit in Havuzönüdamı innerhalb des Territoriums von Phaselis erwähnt (SEG LII 1409: $\mathrm{O} \tau \alpha|v \varepsilon 1 \mathrm{~N} \varepsilon \mu \beta 1| \mu \mathrm{ov})$.

Der Name wird als der Name eines Offiziers im ptolemaischen Dienst auf einer Weihinschrift (9 Juli 116 v. Chr.) aus einer ägyptischen Stadt Philai

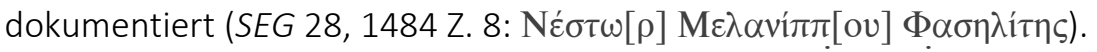

Der Name liegt auf einer Graffiti aus der hellenistischen Zeit in ägypti- 


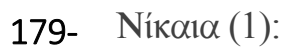

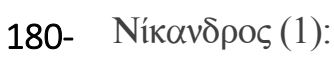

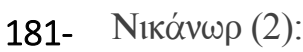

182- Nıќ́pпs (1):

183- Nikíwv (1):

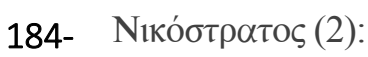

185- Níkwv (1):

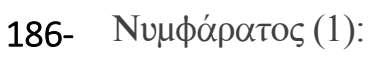

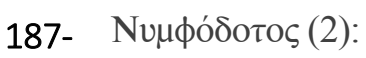

188- Envíwv (1):

189- "Оßрцоь (1):

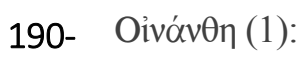

191- 'Ovót

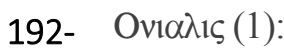

193- "Ovi $\alpha \lambda \lambda 1 \varsigma(1):$

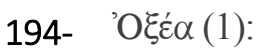

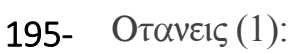

schen Stadt Abydos vor (SEG 26, 1711: Néwv $\Phi \alpha \sigma \eta \lambda i \tau[\eta\rceil])$.

Der Name ist in einer Grabinschrift (I Jhdt. v. Chr. - I. Jhdt. n. Chr.) aus

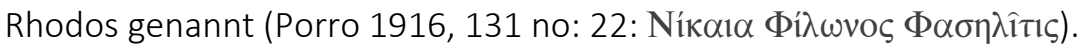

Der Name wird in einer Weihinschrift an Athena Polias (V. Jhdt. v. Chr.)

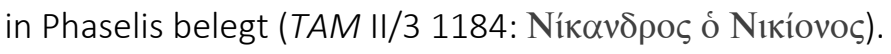

Der Name kommt auf den Münzen (ca. 250-220 v. Chr.) vor (HeippTamer 1993, 135 no: 97 taf. 5 und 140 no: 156-159 taf. 9).

Der Name wird in einer Weihinschrift an Hestia und Hermes (IV. Jhdt. v.

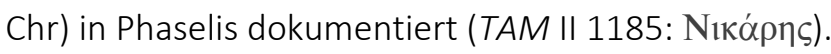

Der Name wird in einer Weihinschrift an Athena Polias (V. Jhdt. v. Chr.)

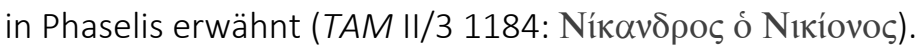

Der Name wird für einen Vater und seinen Sohn in einer Grabinschrift (die hellenistische - römische Zeit) aus Rhodos dokumentiert (IG XII 1no:

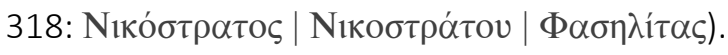

Der Name kommt auf einer Münze (ca.167-130 v. Chr.) vor (HeippTamer 1993, 157 no: 333 taf. 26).

Der Name kommt auf einer Münze (ca.167-130 v. Chr.) vor (HeippTamer 1993, 158 no: 347 taf. 27).

Der Name wird in einer Grabinschrift (III-II Jhdt. v. Chr.) in Phaselis (TAM

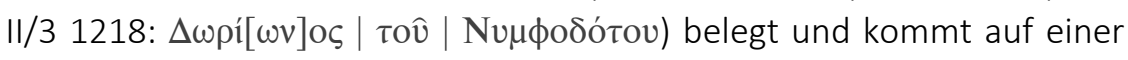
Münze (ca.167-130 v. Chr.) vor (Heipp-Tamer 1993, 158 no: 354 taf. 28).

Der Name kommt auf den Münzen (ca.167-130 v. Chr.) vor (HeippTamer 1993, 159 no: 361-363 taf. 29).

Der Name wird in einer Ehreninschrift (II-III. Jhdt. n. Chr.) aus Phaselis dokumentiert ( Tüner Önen 2015, 27 f. no: 1: 'Oßpínov)

Der Name wird in einer Grabinschrift (II-I. Jhdt. v. Chr.) aus Selimiye innerhalb der rhodischen Peraia belegt (IRhodPer 81 no: 262: Oivóv $\theta \eta \varsigma \mid$ $\Phi \alpha \sigma \eta \lambda \varepsilon i ́ \tau 1 \delta \circ \varsigma)$.

Der Name kommt auf einer Münze (ca.167-130 v. Chr.) vor (HeippTamer 1993, 158 no: 351 taf. 28).

Der Name wird in einer Weihinschrift aus der Kaiserzeit in Havuzönüdamı innerhalb des Territoriums von Phaselis erwähnt (SEG LII 1408:

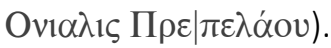

Der Name wird in den zwei Agoninschriften (III. Jhdt. n. Chr.) aus Phaselis

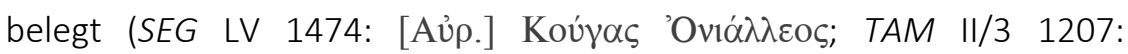

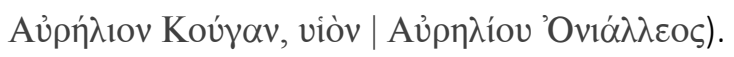

Der Name wird in einer Grabinschrift (III. Jhdt. n. Chr.) aus Olympos

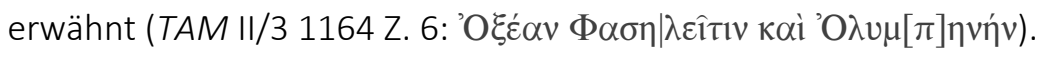

Der Name ist in einer Weihinschrift aus der Kaiserzeit in Havuzönüdamı innerhalb des Territoriums von Phaselis genannt (SEG LII 1409: O $\tau \alpha \mid v \varepsilon 1$ 


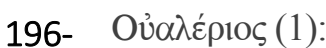

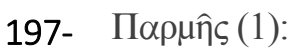

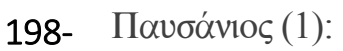

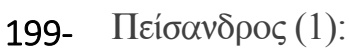

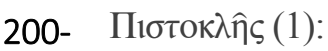

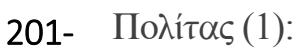

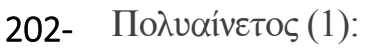

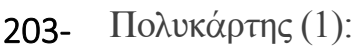

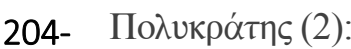

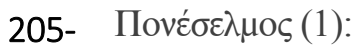

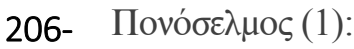

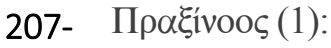

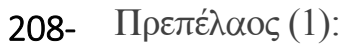

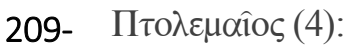

$\mathrm{N} \varepsilon \mu \beta 1 \mid \mu о v)$.

Der Name wird in einer Weihinschrift aus der Kaiserzeit in Mnara innerhalb des Territoriums von Phaselis erwähnt (SEG LII 1441:

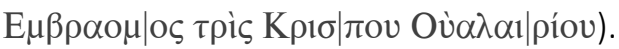

Der Name kommt auf einer Münze (ca.167-130 v. Chr.) vor (HeippTamer 1993, 158 no: 352 taf. 28).

Der Name kommt auf einer Münze (ca.167-130 v. Chr.) vor (HeippTamer 1993, 156 no: 329 taf. 26).

Der Name kommt auf einer Münze (ca.250-220 v. Chr.) vor (HeippTamer 1993, 134 no: 86 taf. 5).

Der Name ist in einer Grabinschrift (hell.-röm.) aus Rhodos genannt

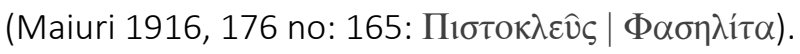

Der Name kommt auf den Münzen (ca.250-220 v. Chr.) vor (HeippTamer 1993, 137 no: 122-123 taf. 7).

Der Name wird in einer Weihinschrift an Athena Polias (V. Jhdt. v. Chr.)

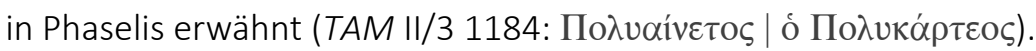

Der Name wird in einer Weihinschrift an Athena Polias (V. Jhdt. v. Chr.)

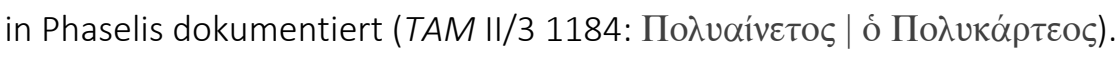

Der Name wird in einer Inschrift aus der 185 v. Chr. aus Rhodos (SEG 39,

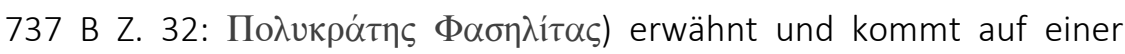
Münze (ca.167-130 v. Chr.) vor (Heipp-Tamer 1993, 159 no: 365 taf. 29).

Der Name wird in den zwei Agoninschriften (III. Jhdt. n. Chr.) aus Phaselis

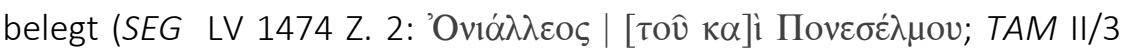

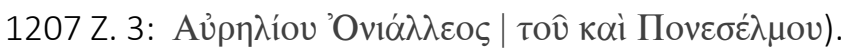

Der Name wird in einer Weihinschrift aus der Kaiserzeit in Havuzönüdamı innerhalb des Territoriums von Phaselis erwähnt (SEG LII

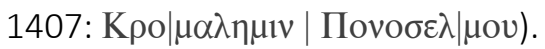

Der Name kommt auf einer Münze (ca.250-220 v. Chr.) vor (HeippTamer 1993, 134 no: 92 taf. 5).

Der Name liegt auf einer Weihinschrift aus der Kaiserzeit in Havuzönüdamı innerhalb des Territoriums von Phaselis vor (SEG LII 1408: Ovia $\lambda$ is $\Pi \rho \varepsilon \mid \pi \varepsilon \lambda \dot{\alpha}(0)$.

Den Namen trugen vier Bürgern von Phaselis:

1-2) In einer Agoninschrift (III. Jhdt. n. Chr.) aus Phaselis (TAM II/3 1206

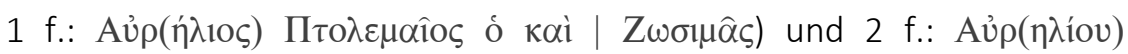

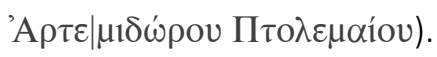

3-4) In einer Ehreninschrift (I-II Jhdt. n. Chr.) aus Phaselis (TAM II/3 1200

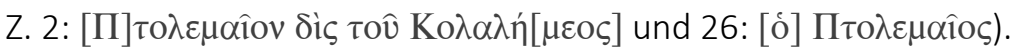

210- 'Ро́ठıлтоৎ (1): Der Name erscheint in einer Grabinschrift (die hellenistische - römische

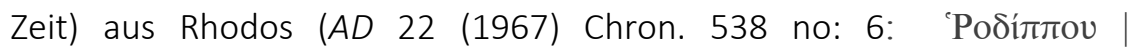




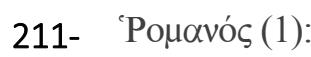

212- 'Poúфeıvos (1):

213- $\quad \Sigma \varepsilon \rho \alpha \pi i ́ \omega \nu(2):$

214- $\quad$

215- $\Sigma \mathrm{o} \lambda \alpha \mu 1 \varsigma(1)$ :

216- इúpos (1):

217- $\quad \Sigma \omega \kappa \rho \alpha \tau i ́ \delta \alpha \varsigma(1):$

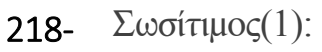

219- $\Sigma \omega \tau \hat{\alpha} \varsigma(1):$

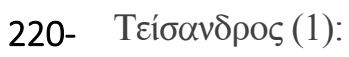

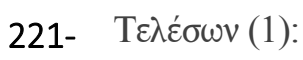

222- Тврті́ (1):

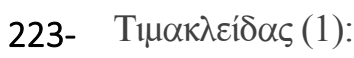

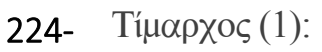

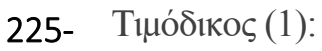

$\Phi \alpha \sigma \eta \lambda i \tau \alpha)$.

Der Bischof von Phaselis, der in dem Jahr 381 n. Chr. an Konzil von Konstantinopolis teilnahm, trug den Namen (Turner 1914, 170:

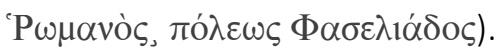

Der Name wird als Cognomen für eine Bürgerin von Phaselis in zwei In-

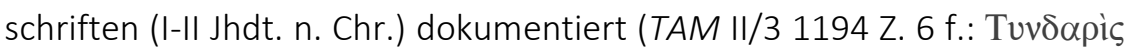

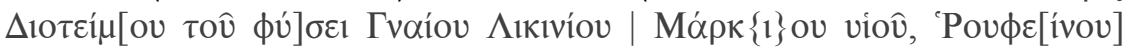

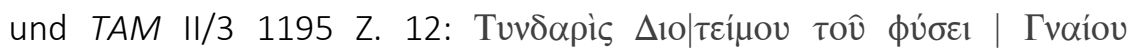

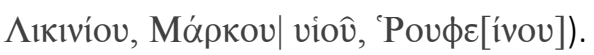

Der Name wird für zwei Personen -der Vater und der Sohn- auf einer Bauinschrift (III. Jhdt. n. Chr.) aus Phaselis belegt (Tüner Önen 2015, 34

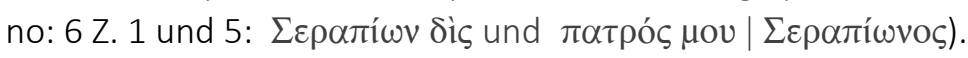

Der Name erscheint auf einer Grabinschrift aus der Kaiserzeit in Armutçuk innerhalb des Territoriums von Phaselis (SEG LII 1411: $\Sigma o \lambda \alpha \mu 1 \mu 1 \zeta)$.

Der Name wird in einer Grabinschrift aus der Kaiserzeit in Armutçuk innerhalb des Territoriums von Phaselis erwähnt (SEG LII 1411: $\Sigma o \lambda \alpha \mid \mu \varepsilon 1)$.

Der Name wird in einer Grabinschrift aus der Kaiserzeit in Phaselis belegt (TAM II/3 1210 Z. 5: इúpos)

Der Name kommt auf den Münzen (ca. 167-130 v. Chr.) vor (HeippTamer 1993, 158 no: 346 taf. 27 ( $\Sigma \omega \beta \rho \alpha \tau i ́ \delta \alpha \varsigma)$ und 160 no: 374 taf. 29).

Der Name kommt auf einer Münze (ca. 250-220 v. Chr.) vor (Peus sale 340 (1994) 416).

Der Name wird in einer Weihinschrift (IV. Jhdt. V. Chr.) in Phaselis belegt

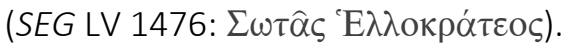

Der Name kommt auf den Münzen (ca.250-220 v. Chr.) vor (HeippTamer 1993, 139 no: 144-146 taf. 8).

Der Name kommt auf einer Münze (ca.167-130 v. Chr.) vor (HeippTamer 1993, 157 no: 343 taf. 27).

Der Name wird als Aliasname in einer Ehreninschrift aus der Kaiserzeit in

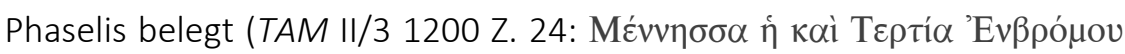
Sic).

Der Name wird in einer Grabinschrift (II-I. Jhdt. v. Chr.) aus Phaselis

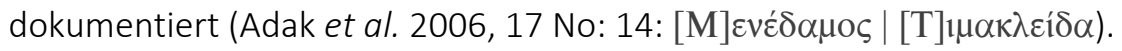

Der Name kommt auf den Münzen (ca.250-220 v. Chr.) vor (HeippTamer 1993, 135 f. no: 107-108 taf. 6).

Diesen Name bezeugt eine Inschrift (ca. 400 v. Chr.) aus Delphi. Der Bürger von Phaselis wurde als theoros nach Delphi gesandt (CIDelph I, 23 ff. no: 8 Z. 5: Tıнобíко). 


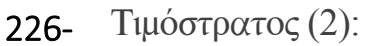

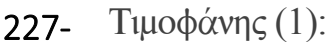

228- Tíuwv (2):

229- Tiбías (1):

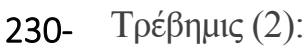

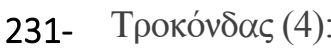

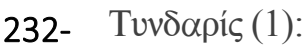

233- $\Phi i ́ \lambda \omega v(1)$ :

234- $\Phi 1 \lambda \dot{\omega} \tau \alpha \varsigma$ (2):

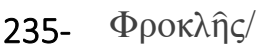
Прок入йৎ (1):

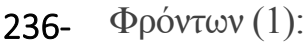

Der Name wird in einer Grabinschrift aus der hellenistischer Zeit (?) aus

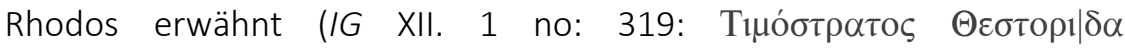
$<\Phi>\alpha \varsigma<\eta>\lambda<i>\tau \alpha[\zeta])$ und kommt auf einer Münze (ca.167-130 v. Chr.) vor (Heipp-Tamer 1993, 157 no: 342 taf. 27).

Der Name ist in einer Proxenie-Dekret (322-306 v. Chr.) aus Samos ge-

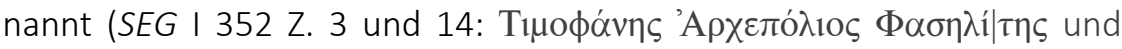

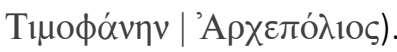

Der Name kommt auf den Münzen (ca.250-220 und 167-130v. Chr.) vor (Heipp-Tamer 1993, 136 f. no: 115-121 taf. 6 f. und 157 no: 337 taf. 27).

Der Name wird in einer Inschrift (ca. 157 v. Chr) aus Delos erwähnt

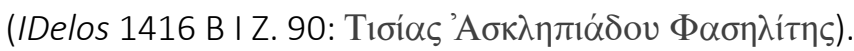

Der Name erscheint in einer Grabinschrift aus der Kaiserzeit in Phaselis

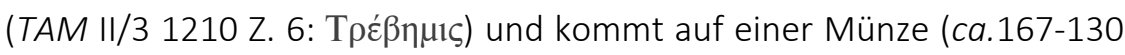
v. Chr.) vor (Heipp-Tamer 1993, 157 no: 344 taf. 27).

Der Name wird viermal dokumentiert:

1-2) In den zwei Grabinschriften aus der Kaiserzeit in Phaselis (TAM II/3

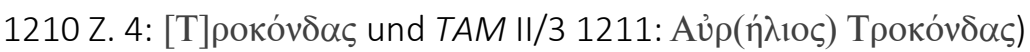

3) In einer Grabinschrift (III. Jhdt. n. Chr.) aus Territorium von Phaselis

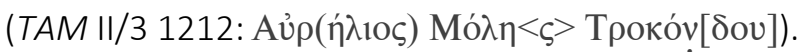

4) In einer Weihinschrift aus der Kaiserzeit in Mnara innerhalb des

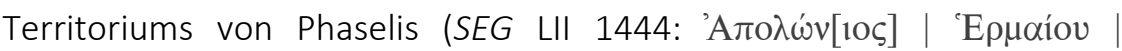

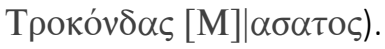

Der Name wird für eine Bürgerin von Phaselis in zwei Inschriften (I-II

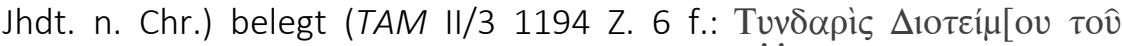

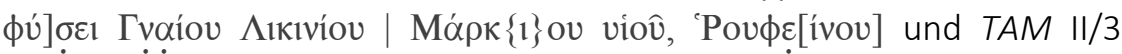

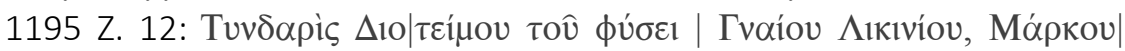
vioû, ${ }^{\circ}$ Pouфe[ívou]).

Der Name wird in einer Grabinschrift (I Jhdt. v. Chr. - I. Jhdt. n. Chr.) aus

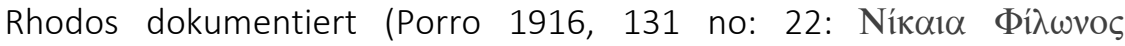
$\Phi \alpha \sigma \eta \lambda \hat{\imath} \tau \imath \varsigma)$.

Der Name wird für einen Vater und einen Sohn in einer Inschrift aus Delos aus dem Jahr 123 v. Chr. erwähnt, die eine Weihung von Epheben

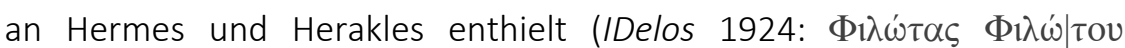
$\Phi \alpha \sigma \eta \lambda i ́ \tau\rceil)$.

Der Name wird in einer Grabinschrift (II.-III. Jhdt. n. Chr.) aus Phaselis

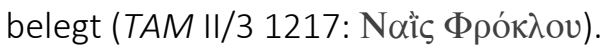

Der Bischof von Phaselis, der in dem Jahr 451 n. Chr. an Konzil von Khalkedon teilnahm, trug den Namen (ACO II 1. 1, 62 no: 237

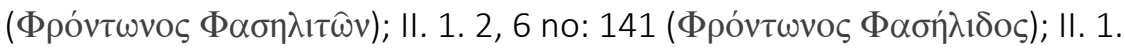

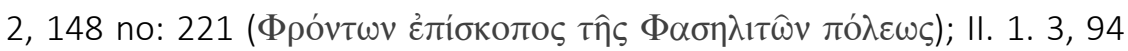




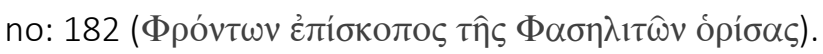

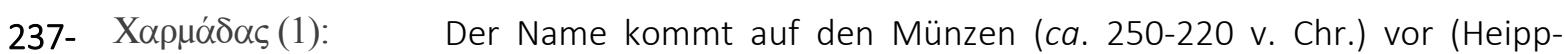
Tamer 1993, 135 no: 102-103, taf. 6).

238- X X $\alpha \mu i ́ \delta\rceil \varsigma$ (1): Der Name ist in einer Grabinschrift (IV. Jhdt. v. Chr.) aus Athen genannt

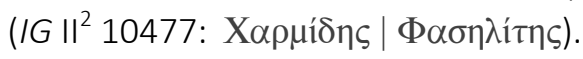

239- Xapuıws (1): Der Name kommt auf den Münzen (ca. 167-130 v. Chr.) vor (HeippTamer 1993, 159 no: 370-371 taf. 29).

240- Xopєiós (1): Der Name kommt auf einer Münze (ca. 250-220 v. Chr.) vor (HeippTamer 1993, 137 no: 126 taf. 7). 


\section{BIBLIOGRAPHIE UND ABKURZÜNGEN}

\section{Antike Quellen}

Ael. Herod. Pros. Cath.

Athen. Deip.

Cic. In Verr.

Cic. Leg. Agr.

Demosth. Contr. Lacr.

Diod. Bibl.

Dion. Per

Eustath. Dion. Per.

Etym. Mag.

Eutr. Brev.

Flor. epit.

Hdt.

Luc. Bell. civ.

Mela

Oros. hist.

Plin. Nat. Hist.
(= Aelius Herodianus, De Prosodia Catholica)

Kullanılan Metin: Aelius Herodianus, De Prosodia Catholica. Ed. A. Lentz, Grammatici Graeci, vol. 3/1. Leipzig 1867.

(= Athenaios, Deipnosophistai)

Kullanılan Metin: Athenaios, Deipnosophistai. Ed. G. Kaibel, Athenaei Naucratitae Deipnosophistarum libri XV. 3 volumes. Stuttgart 1965-1966.

(= Cicero, In Verrem)

Kullanılan Metin: In Verrem, M. Tulli Ciceronis Orationes. Vol. 3. Ed. W. Peterson. Oxford 1917.

(= Cicero, De Lege Agraria)

Kullanılan Metin: De Lege Agraria, M. Tulli Ciceronis Orationes. Vol. 4. Ed.

A. C. Clark. Oxford 1909.

(= Demosthenes, Contra Lacritum)

Kullanılan Metin: Demosthenes, Contra Lacritum. Ed. W. Rennie, Demosthenis Orationes. Vol. 2/2. Oxford 1921.

(= Diodoros Siculus, Bibliotheke Historike).

Kullanılan Metin ve Çeviri: Diodoros Siculus, Bibliotheke Historike. Eds. C.

H. Oldfather, C. L. Sherman, C. B. Welles, R. M. Geer - F. R. Walton. Diodoros of Sicily Volumes I-XI. London - New York 1947-1970.

(= Dionysios Periegetes, Orbis Descriptio)

Kullanılan Metin: Dionysios von Alexandria. Das Lied von der Welt. Ed. K. Brodersen. Hildesheim 1994.

(= Eustathios, Commentarium in Dionysii Periegetae Orbis Descriptionem) Kullanılan Metin: Commentarium in Dionysii Periegetae Orbis Descriptionem. Ed. K. Muller, Geographi Graeci Minores. Volume 2. Paris 1861.

(= Etymologicum Magnum)

Kullanılan Metin: Etymologicum Magnum. Ed. T. Gaisford. Oxford 1848.

(= Eutropius, Brevarium ab Urbe Condita)

Kullanılan Metin: The Breviarum ab Urbe Condita of Eutropius. Ed. H. W. Bird. Liverpool 1993.

(= Annius Florus, L. Annaei Flori Epitoma)

Kullanılan Metin: L. Annaei Flori Epitoma De Tito Livio Bellorum Omnium Annorum DCC Libri II. Ed. E. S. Foster, Lucius Annaeus Florus The Two Books of the Epitome, Extracted from Titus Livius, of All the Wars of Seven Hundred Years. London - New York 1929.

(= Herodotos, Historiae)

Kullanılan Metin ve Çeviriler: Herodotus, The Persian Wars. Volumes I-IV. Ed. A. D. Godley. London - New York 1975.

Herodot Tarihi. Çev.: M. Ökmen. İstanbul $1991^{3}$.

(= Lucanus, Bellum Civile)

Kullanılan Metin: M. Annaei Lucani Belli Civilis Libri Decem. Ed. A. E. Housman. Oxford 1927.

(= Pomponius Mela, De Chronographia)

Kullanılan Metin: Pomponius Mela. Kreuzfahrt durch die Alte Welt. Ed. K. Brodersen. Darmstadt 1994.

(= Orosius, Historiarum Adversus Paganos)

Kullanılan Metin: Orosius, Seven Books of History against the Pagans. Ed.

I. W. Raymond. New York 1936.

(= G. Plinius Secundus, Naturalis Historia)

Kullanılan Metin: Pliny Natural History, Volumes I-X. Eds. H. R. Rackham, 
Plut. Mor.

Schol. Nic.

Sch. Pind.

Sch. Thuc

Steph. Byz. Eth.

Strab.

sud.

\section{Moderne Literatur}

$A A A$

ACO

$A D$

Adak 2007a

Adak 2007b

Adak 2013

Adak et.al 2006

ArchEph

Arslan 2003

ASAA

Baillet 1926
W. H. S. Jones - D. E. Eichholz. Cambridge, Massachusetts - London 19381971.

(= Plutarkhos, Moralia)

Kullanılan Metin ve Çeviri: Plutarch's Moralia, Volumes I-XIV. Trans.: F. C. Babbitt - W. C. Helmbold. London - New York 1928-1967.

(= Scholia in Nicandrum)

Kullanılan Metin: Scholia Theriaca (Scholia Vetera et Recentiora). Scholia in Nicandri Theriaka. Ed. A. Crugnola. Milano 1971.

(= Scholia in Pindarum)

Kullanılan Metin: Scholia in Pindarum Scholia Vetera. Scholia Vetera in Pindari Carmina. 3 Volumes. Ed. A. B. Drachmann. Leipzig 1903-1927.

(= Scholia in Thucydidem)

Kullanılan Metin: Scholia vetera et recentiora. Ed. K. Hude, Scholia in Thucydidem ad Optimos Codices collata. Leipzig 1927.

(= Stephanos Byzantios, Ethnika)

Kullanılan Metin: Stephan von Byzanz, Ethnika. Ed. A. Meineke. Berlin 1849.

(= Strabon, Geographika)

Kullanılan Metin ve Çeviriler: The Geography of Strabo. Volumes I-VIII. Ed. \& Trans.: H. L. Jones. London - New York 1917-1932.

Strabon, Coğrafya. Çev.: A. Pekman. İstanbul 2000.

(= Suda-Suidas, Suidae Lexicon)

Kullanılan Metin: Suda-Suidas, Suidae Lexicon. Volumes I-IV. Ed. A. Adler. Leipzig - Teubner 1928-1971.

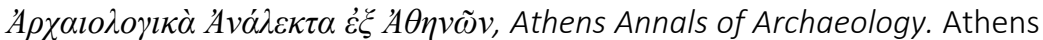
1968-

Acta Conciliorum Oecumenicorum. Berlin - Leipzig 1914-1940. Archaiologikon Deltion. Athen 1915-1935; 1960-.

M. Adak, "Die Dorische und Aolische Kolonisation des Lykisch-Pamphylischen Grenzraumes im Lichte der Epigraphik und der Historischen Geographie". Ed. C. Schuler, Griechische Epigraphik in Lykien. Eine Zwischenbilanz. Atken des internationalen Kolloquiums München, 24-26. Februar 2005. Wien (2007) 41-50.

M. Adak, "Die Rhodische Herrschaft in Lykien und die Rechtliche Stellung der Städte Xanthos, Phaselis und Melanippion". Historia 56/3 (2007) 251279.

M. Adak, "Names, Ethnicity and Acculturation in the Pamphylian-Lycian Borderland". Ed. R. Parker, Personal Names in Anatolia. Proceedings of the British Academy 191. Oxford (2013) 63-78.

M. Adak, N. Tüner Önen - S. Şahin, "Neue Inschriften aus Phaselis". Gephyra 2 (2006) 1-20.

Archaiologike Ephemeris. Athens 1910-.

M. Arslan, "i.Ö. 188 Yılından I.Ö. 67 Yılına Kadar Lykia, Pamphylia ve Kilikia Trakheia Sahillerindeki Korsanlık Faaliyetleri: Nedenleri ve Sonuçları". Adalya VI (2003) 91-118.

Annuario Della (Regia) Scuola Archeologica di Atene e Delle Missioni Italiane in Oriente, 1-16 (Bergamo etc. 1914-1942); NS I- Rome 1942-.

M. J. Baillet, Inscriptions Grecques et Latines des Tombeaux des Rois ou Syringes. Kairo 1926. 
66

Blackman 1981

Blinkenberg 1941

Bresson 2000

Briant - Descat 1998

$\mathrm{CH} \mathrm{VI}$

CIDelph. I

CIDelph. II

Dikander 1839

FGrHist

Fraser 1977

von Gaertringen 1896

FPL

Heipp-Tamer 1993

Hurter - Pásztory 1984

I.Delos

$\mathrm{IGCH}$

I.lasos

IOrop.

IRhodPer

Jacopi 1932

Jameson 2000-2003

Klee 1918

Kraay 1976

Kraay 1977

Kraay - Moorey 1968

Lanz Sale

Malkin 2011

Maiuri 1916

\section{Nihal TÜNER ÖNEN}

D. J. Blackman, "The Inscriptions". Ed. J. Schäfer, Phaselis. Beiträge zur Topographie und Geschichte der Stadt und ihrer Häfen. Tübingen (1981) 138-163.

C. Blinkenberg, Lindos II. Inscriptions. Berlin - Copenhagen 1941.

A. Bresson, La Cité Marchande. Ausonius 2000.

P. Briant - R. Descat, "Un Registre Douanier de la Satrapie d’Égypte à l'époque Achéménide (TAD C3,7)". Eds. N. Grimal - B. Menu, Le Commerce en Égypte Ancienne. Le Caire (1998) 59-104.

Coin Hoards VI. Ed. M. J. Price. London 1981.

G. Rougemont, Corpus des Inscriptions de Delphes I. Lois Sacrées et Règlements Religieux. Paris 1977.

J. Bousquet, Corpus des Inscriptions de Delphes II. Les Comptes du Quatrième et du Troisième Siècle. Paris 1989.

G. E. Dikander, Des M. Annaeus Lucanus Pharsalia oder Bürgerkrieg zwischen Caesar und Pompeius, Epos aus der Römerzeit in 10 Büchern. Stade 1839.

Die Fragmente der Griechischen Historiker. Volumes I-XV. Ed. F. Jacoby. Berlin - Leiden 1923-1958.

P. M. Fraser, Rhodian Funerary Monuments. Oxford 1977.

F. Hiller von Gaertringen, "Inscriften aus Rhodos". AM 21 (1896) 39-66.

Fixed Price Lists. I- Amerongen. Ed. G. Henzen. Netherlands 1989-

C. Heipp-Tamer, Die Münzprägung der Lykischen Stadt Phaselis in Griechischer Zeit. Saarbrücker Studien zur Archäologie und Alten Geschichte 6. Saarbrücken 1993.

S. Hurter - E Pásztory, Archaischer Silberfund aus dem Antilibanon, Festschrift für Leo Mildenberg. Wetteren 1984.

Inscriptions de Delos. 7 Volumes. Eds. A. Plassart, J. Coupry, F. Durrbach, P. Roussel - M. Launey. Paris 1926-1950.

Inventory of Greek Coin Hoards.

Die Inschriften von lasos. 2 Volumes. Ed. W. Blumel. Bonn 1985.

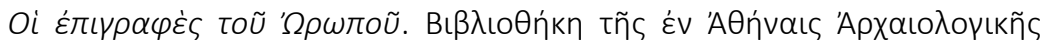
'Etaıpzias 170. Ed. B. C. Petrakos. Athens 1997.

Die Inschriften der Rhodischen Peraia. Ed. W. Blümel. Bonn 1999.

G. Jacopi, "Nuove Epigrafi dalle Sporadi Meridionali". Clara Rhodos 2 (1932) 169-255.

M. H. Jameson, "Athens and Phaselis, IG I 10 (EM 6918)". Horos 14-16 (2000-2003) 23-29.

T. Klee, Zur Geschichte der Gymnischen Agone an Griechischen Festen. Berlin 1918.

C. M. Kraay, Archaic and Classical Greek Coins. London 1976.

C. M. Kraay, "The Asyut Hoard: Some Comments on Chronology". NC 17 (1977) 189-198.

C. M. Kraay - P. R. S. Moorey, "Two Fifth Century Hoards from the Near East". RN 10 (1968) 181-235.

Numismatik Lanz, München, Sale Catalogues. 14- (Munich 1978- ); Continues Kastner Sales.

I. Malkin, A Small Greek World: Networks in the Ancient Mediterranean. Oxford 2011.

A. Maiuri, "Nuove Iscrizioni Greche dalle Sporadi Meridionali". ASAA 2 (1916) 133-179. 
Maiuri 1925

$\mathrm{MJH}$

Möller 2000

Ormerod - Robinson 1914

Peus Sale

Porro 1916

Pugliese-Carratelli 1939/1940

Robinson 1930

Robert 1963

Roma Sale

SERod.

Suppl. Rod.

Şahin - Adak 2013

Tekin 2012

TrGF I

Tüner Önen 2008

Tüner Önen 2012a

Tüner Önen 2012b

Tüner Önen 2015

Turner 1914

Zgusta 1964
A. Maiuri, Nuova Silloge Epigrafica di Rodi e Cos. Florence 1925.

Akdeniz Üniversitesi, Edebiyat Fakültesi, Akdeniz Insani Bilimler Dergisi / Mediterranean Journal of Humanities. Antalya.

A. Möller, Naukratis Trade in Archaic Greece. Oxford 2000.

H. A. Ormerod - E. S. G. Robinson, "Inscriptions from Lycia". JHS 34 (1914)

1-35.

B. Peus, Sale Catalogues 241-. Frankfurt 1941-.

G. G. Porro, "Iscrizioni di Rodo". ASAA 2 (1916) 125-131.

G. Pugliese-Carratelli, "Per la Storia delle Associazioni in Rodi Antica". ASAA NS 1-2 (1939-1940) 147-200.

E. S. G. Robinson, "A find of Archaic Greek Coins from the Delta". NC 5th. Series 10 (1930) 93-106.

L. Robert, Noms Indigènes de l'Asie Mineure Gréco-Romaine I. Paris 1963.

Roma Numismatics Ltd. Roma I. London 2010-.

G. Pugliese Carratelli, "Supplemento Epigrafico Rodio". ASAA 30-32 (= NS. 14-16) (1952-1954) 247-316.

G. Pugliese-Carratelli, "Supplemento Epigrafico Rodio". ASAA NS 14-16 (1952-1954) 247-316.

S. Şahin - M. Adak, Stadiasmus Patarensis. Itinera Romana Provinciae Lyciae Likya Eyaleti Roma Yolları. İstanbul 2013.

O. Tekin, Konuşan Paralar - Talking Coins. İstanbul 2012.

Tragicorum Graecorum Fragmenta. Vol. 1: Didascaliae Tragicae, Catalogi Tragicorum et Tragoediarum, Testimonia et Fragmenta Tragicorum Minorum. Ed. B. Snell. Göttingen 1971.

N. Tüner Önen, Phaselis Antik Kenti ve Teritoryumu. Yayınlanmamış Doktora Tezi, Akdeniz Üniversitesi. Antalya 2008.

N. Tüner Önen, "Ideas Concerning the Historical Identity and the Connections of the City of Phaselis an Eastern Mediterranean Port". MJH II/1 (2012) 205-212.

N. Tüner Önen, "Yazıtlar Işığında Phaselis". Ed. K. Dörtlük, T. Kahya, R. Boyraz Seyhan - T. Ertekin, Uluslararası Genç Bilimciler Buluşması I. Anadolu Akdeni Sempozyumu 04-07 Kasım 2009 Antalya Sempozyum Bildirileri. İstanbul (2012) 479-482.

N. Tüner Önen, "Yeni Buluntular Işığında Phaselis Epigrafi Çalışmaları". Phaselis I (2015) 19-38.

C. H. Turner, "Canons Attributed to the Council of Constantinople, A.D. 381, Together with the Names of the Bishops, from two Patmos MSS POB' POÃ'”. The Journal of Theol. Stud. 15 (1914) 161-178.

L. Zgusta, Kleinasiatische Personennamen. Prag 1964. 